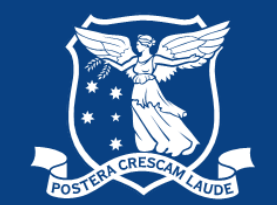

THE UNIVERSITY OF

MELBOURNE

Melbourne Medical School

Department of Medical Education

\title{
Evaluation of a mobile learning platform for clinical supervision
}

Report prepared for the Melbourne Centre for Academic Health

April 2021

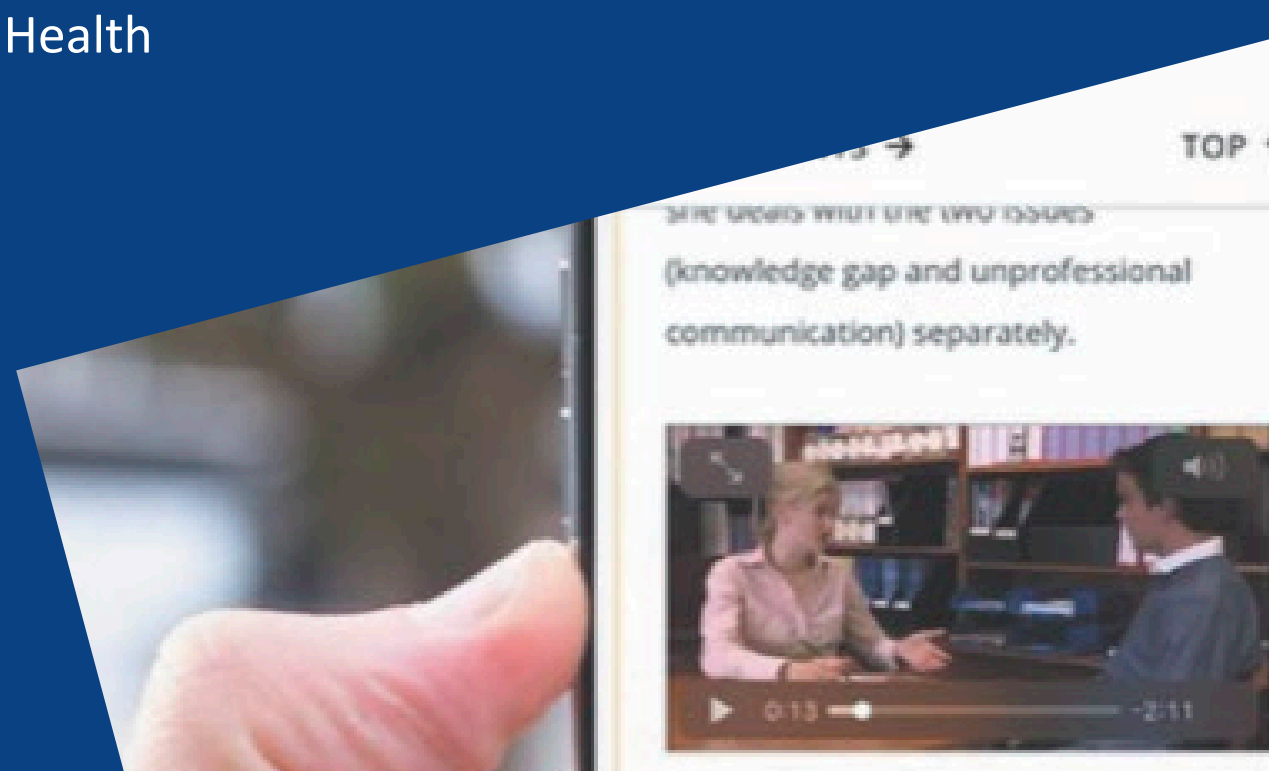

When Claire asked Declan how he felt about their interaction that moming, what did his response tell her?

A. that he is inherently rude and beyond redemption

B. that his language skills mean that people misinterpret what he's saying

C. that he at least had some insight to the eflect he'd had on her 


\section{Table of Contents}

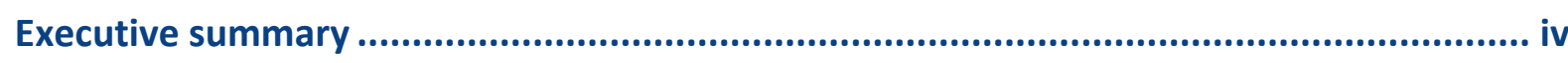

The Clinical Supervision Online (CSO) course: Context and an outline ............................ 1

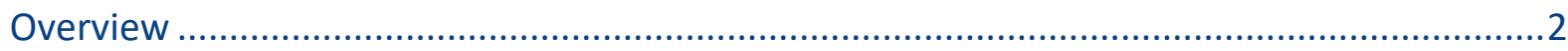

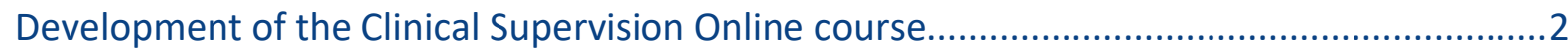

Overview of participation in the Clinical Supervision Online (CSO) course.............................3

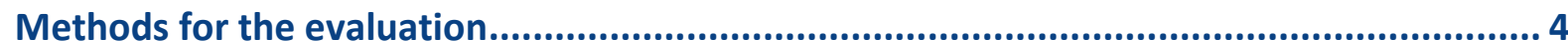

Methodological challenges, decisions and limitations ......................................................

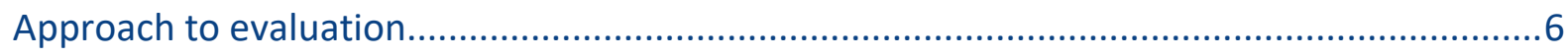

Data informing the evaluation of the Clinical Supervision Online (CSO) course ......................7

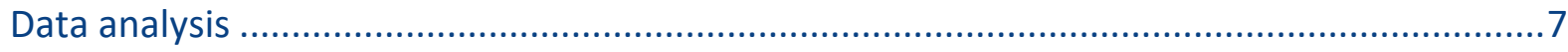

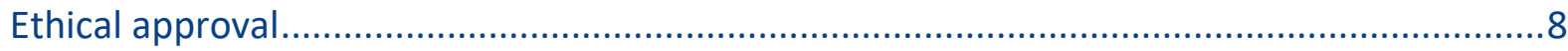

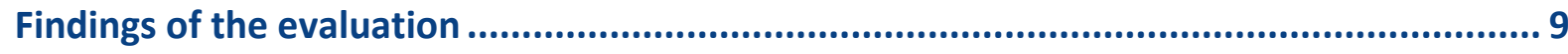

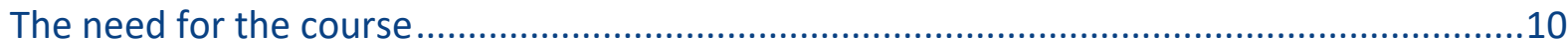

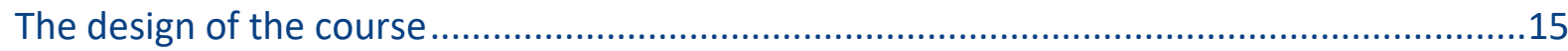

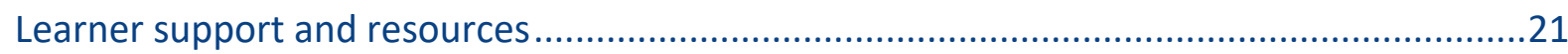

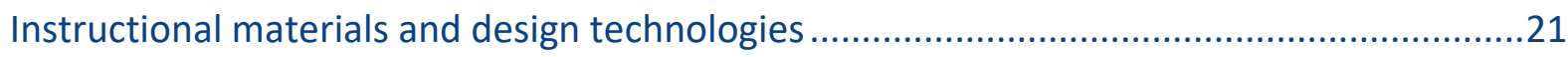

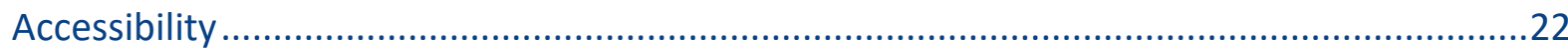

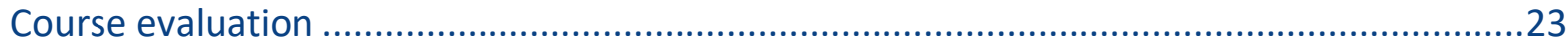

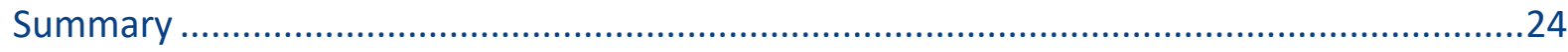

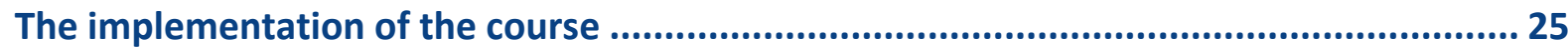

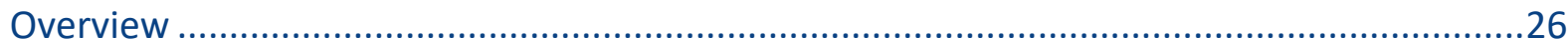

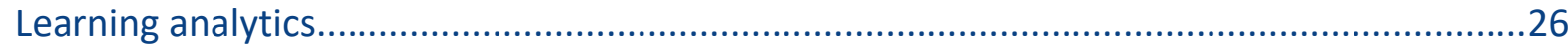

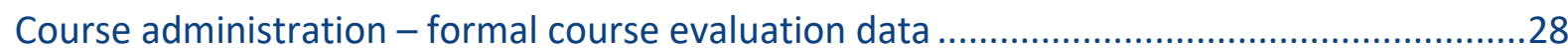

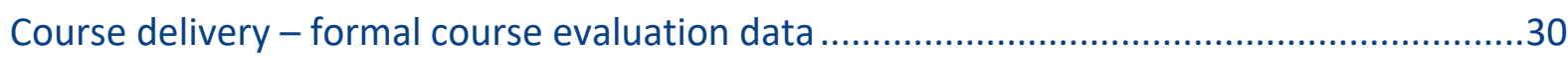

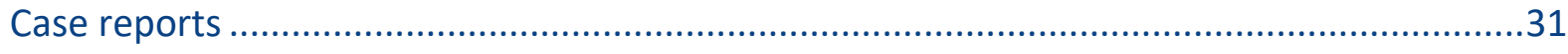

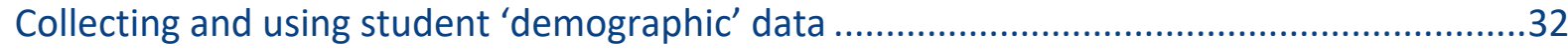

Course impact - formal course evaluation data.............................................................33

Post-tutorial assessments and case studies star-ratings textbox........................................34

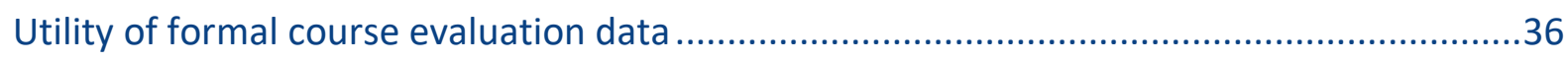

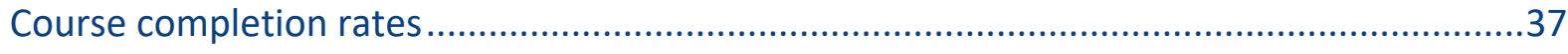

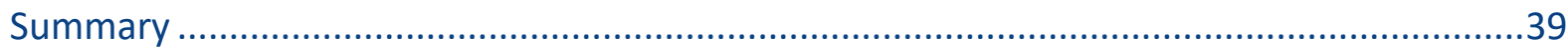


The cost-effectiveness of the course: Return on investment ........................................ 40

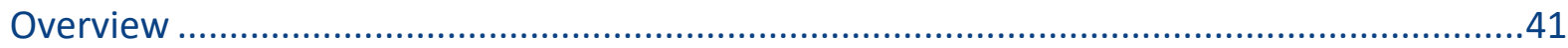

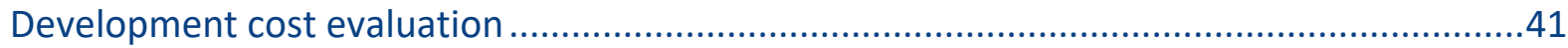

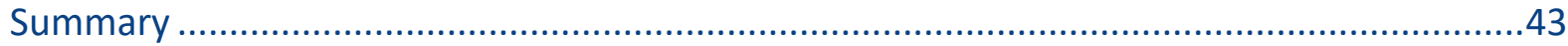

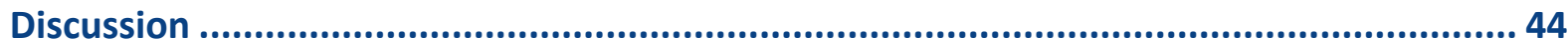

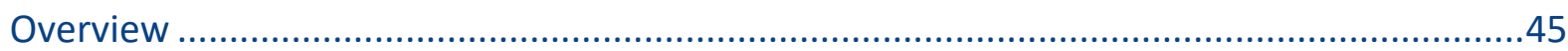

How well does the Mobile Learning Unit discharge its responsibilities? ..............................45

Who is responsible for clinical supervisor professional development? .................................45

Is the CSO course a reasonable 'solution' to the problem of supervisor professional

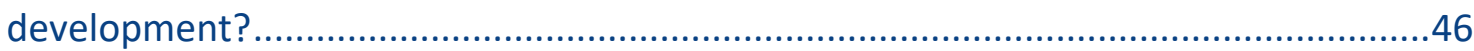

Future possibilities: Learning design, research, and evaluation ..........................................48

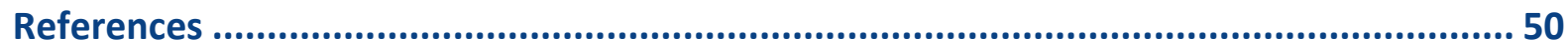

Appendix A - Quality Online Course Initiative (QOCI) Rubric ........................................ 53

Appendix B - Embedded Course Evaluation .................................................................... 57 


\section{Executive summary}

\section{Context}

This report details a formative evaluation of the Clinical Supervision Online (CSO) course, a fee-paying (\$350.00), fully online 'light touch' program of study for clinical supervisors offered by the Melbourne Medical School, which was developed in conjunction with the University's Mobile Learning Unit. The course requires between six to ten hours of self-directed study and is designed for any clinicians who teach.

\section{Methods}

Evaluation of the course was guided by Rossi, Lipsey and Freeman's (2004) approach to program evaluation, addressing the need for the course, its design, implementation, impact, and return on investment. Data were collected from multiple data sources including interviews with key informants, document analysis, an embedded student survey, learning analytics data, financial data, and an audit against 'best practice' standards for online course design.

\section{Findings}

The findings suggest that course development was driven by both a financial imperative and genuine concern to meet training needs of clinical supervisors. Two hundred and four students enrolled on the course in its first 18 months. This has been enough to cover its developmental costs, yet the enrolment numbers were perceived as disappointing. The CSO course is one of many professional development offerings in a competitive marketplace. There remain some unresolved questions about whether the course in its present form could be a stronger performer, particularly in terms of generating income, or whether some of the initial expectations were overly ambitious, based on a less than thorough initial market analysis.

In relation to 64 quality standards for online course design, the level of performance was rated as 'meets' for 44 items; 'exceeds' for one item; 'developing for 13 items'; and, 'non-existent' for six items. An additional 33 items were identified as 'not applicable' for the 'light touch' course design. Meeting $70 \%$ of the items judged relevant for a 'light touch' design suggests that the course has many strengths.

The course's embedded formal evaluation approaches have the appearance of what Patton (2008) labels 'quick and dirty' (Patton, 2008); a low-budget effort, which offers little value for either marketing the course or its development.

Fifty-six (39\%) of the 142 students who had enrolled in the course up until the end of June 2020 were judged not to have completed the course. Sixty-one percent of these non-completing students did not complete a single posttutorial assessment and $96 \%$ of these students did not complete a single end-of-course case study assessment. Only students who completed the course could submit a course evaluation.

Respondents who completed the course evaluation were largely positive about how the course was administered and implemented, reflecting well on the available support from the Online Learning Support Team and the accessibility of the course delivery platforms. The small number of student inquiries, little more than an inquiry a week, is indicative of a successfully implemented 'light touch' course. Students' expectations of the course were met for the vast majority of course evaluation respondents, with most agreeing or strongly agreeing they had applied what they had learned to their day-to-day practice.

The delivery platforms did not have well-developed learning analytics functions and the available data from the Customer Relationship Management (CRM) system was sparse, meaning that little information was available about the students themselves of how they interacted with the course. Available student data suggests a wide range of duration of engagement with the course ('screen time'), although this may be related to how the engagement data is collected.

Although the Mobile Learning Unit manages student communications well, improvements can be made to how it supports continuous improvements to the CSO course, as no summary feedback reports had been created and no review meetings had been held with the Department of Medical Education to discuss the implications of student feedback reports, reappraise the content, or reassess approaches to marketing the course. 


\section{Recommendations}

This evaluation of the CSO course was undertaken with a formative intent. Embedded within the report are numerous suggestions for the course team to consider, many of them arising from judging the CSO course against 'best practice' standards for online course design. The suggestions for improving the existing 'light touch' course are aggregated below:

\section{Instructional design}

1. Signpost the overarching course outcomes in the online course, not solely on the webpage and course brochure, and indicate how tutorial outcomes link to them.

2. Articulate the purpose of all learning activities.

3. Provide a consistent estimate of time to complete the course.

4. State the technical competencies required of students.

5. Provide clearer details about technical requirements required to access the course and ensure that data intensive resources are accessible across a variety of platforms, and accessible with slower internet connections.

6. Confirm that all images that need to be acknowledged, are acknowledged.

\section{Student evaluation and assessment}

7. Consider to what extent it is possible to include assessments that can measure the stated course outcomes without jeopardising the 'light touch' design.

8. Provide clearer guidance about the assessment 'pass mark' and the number of re-takes permitted.

Accessibility

9. Review the entire course against the Web Content Accessibility Guidelines.

10. Ask people with different impairments to review specific aspects of the course, e.g., navigability and use of colours.

11. Embed captions in all graphics (e.g., cartoons and photographs).

12. Provide closed captions on all videos.

13. Provide access to text transcripts for video-content.

\section{Course evaluation}

14. Minimally, correct the wording for the open text box in the Course Impact section of the survey and remove the question about the simulator.

15. Review the feedback options with a view to generating more meaningful data to inform improvements in the CSO course.

16. Review the course evaluation processes, with a view to generating more meaningful information (beyond student 'reaction').

17. Set dates to generate and review formal course evaluation data. Depending upon student numbers this could be every 12- or 24-month period.

\section{Customer Relationship Management (CRM) and learning analytics data}

18. Review the available learning analytics data and establish whether it is possible to refine how this data is collected to improve accuracy (particularly engagement duration).

19. Review the processes for capturing and reporting on student 'demographic' data.

20. Review the data currently being collected, with the aim of enhancing the information to support both educational and marketing functions. Marketing-specific input would be of assistance in this review.

21. Consider how student learning analytics data could be used to inform the course design and support student learning. This requires collecting data that is designed to answer specific questions.

\section{Marketing}

22. Consider undertaking a new and more through market analysis.

23. Explore the place of the CSO course within the current Department of Medical Education and Melbourne Medical School clinical education professional development offerings.

24. Review the marketing strategy for the course, including responsibilities for marketing, and consideration of the potential for the CSO course to be included in specialist medical college professional development. The clinical schools associated with the Melbourne Medical School also presents another opportunity to expand the reach.

25. Review the cost of the course, including consideration of a lower price point to expand access for the breadth of health professions educators. 


\section{Conclusion}

From a learning design perspective there is much to like about the CSO course and the outcome of assessing it against the standards for 'best practice' online course design suggests that an evolutionary approach - making incremental changes - could improve the course whilst retaining its existing 'light touch' format. The related low-impost on the University has been realised, whilst at the same time maintaining good technical support to students. The course has reached a point where there has been a return on investment, which is generating a small amount of income for the Department of Medical Education and the Mobile Learning Unit.

Yet, on the basis of the available data, we are not able to say that the course adds to what students know and understand about clinical supervision, or whether they can apply any new knowledge and understandings to their workplaces. Not completing the course, a significant issue, is also likely to impact on students' knowledge and understanding of the clinical supervisor's role.

Throughout the report, it is questioned whether the CSO course represents a reasonable 'solution' to the problem of clinical supervisors' professional development. Many features of 'best practice' online design, particularly interactions with other clinical supervisors and educators, were deliberately excluded from the CSO course's design in order to maintain its 'light touch' intent. Interactions with educators and other clinical supervisors may lessen course 'dropouts' and be significant sources of support and learning. However, such additions would move the course into 'high touch' territory.

The CSO course on its own is unlikely to realise the depth of achievement implied in the course aims and learning outcomes. In part, this is due to the aforementioned limitations of the 'light touch' design but more significantly due to the insufficient 'volume of learning' built into the course. The CSO course may best be seen as an entrée into the art of clinical supervision. How best to meet the training needs of clinical supervisors remains uncertain.

\section{Limitations}

Significant limitations relate to the type and quality of available data. There were low response rates to some feedback options, raising issues of response bias. No feedback was available from students who did not complete the course. The use of open-ended survey questions generally produces 'thin' qualitative data and self-reported data is unreliable. Detailed financial information was unavailable meaning that we were unable to uncover the true costs of developing the course or obtain an accurate account of operating costs. 


\section{Authors}

Timothy Clement, PhD

Department of Medical Education

Melbourne Medical School

University of Melbourne

tim.clement@unimelb.edu.au

Brett Vaughan, PhD

Department of Medical Education

Melbourne Medical School

University of Melbourne

brett.vaughan@unimelb.edu.au

\section{Suggested reference}

Clement T, Vaughan B. Evaluation of a mobile learning platform for clinical supervision. Melbourne, Australia: University of Melbourne, Department of Medical Education; 2021.

ISBN 9780734056351 


\section{The Clinical Supervision Online (CSO) course: Context and an outline}




\section{Overview}

The CSO course is a fully online 'light touch' program of study for clinical supervisors ${ }^{1}$ developed and offered by the Melbourne Medical School ${ }^{2}$. The course was designed to be incorporated into the suite of professional development offerings for health professions' educators, particularly those involved in clinical education and supervision ('clinical supervisor(s)'). The Melbourne Medical School, through the Department of Medical Education, offers a range of professional development opportunities for clinical supervisors, including one- and two-day day professional development courses through to graduate programs in clinical education from Graduate Certificate to Master's level.

The CSO course aims "to provide the background, understanding and skills for clinicians to create a learning environment within which their learners thrive", focuses on "building knowledge and understanding of the role of a clinical supervisor", and is designed for "all clinicians who teach and/or supervise learners at any level" (Mobile Learning Unit, n.d.-a). The overarching learning outcomes for the CSO course are:

- Demonstrate a critical understanding of the principles of successful clinical supervision.

- Identify resources and techniques available to support clinical supervisors in their workplace and know how to use them most effectively.

- Describe a trainee-centred approach to clinical supervision and training that maximises patient safety.

- Demonstrate an approach to the provision of feedback to clinical learners that results in performance improvement (Mobile Learning Unit, n.d.-a).

\section{Development of the Clinical Supervision Online course}

The development of the CSO course was a collaborative development between the School's Department of Medical Education and the Mobile Learning Unit ${ }^{3}$. The Mobile Learning Unit offers a Continuing Professional Development course development service, where the content experts work with eLearning experts to produce online courses aimed at a professional market. The Mobile Learning Unit also has an ongoing role in course implementation; providing advice on marketing, processing course payments, sending introductory e-mails to students, managing student enquiries, providing technical assistance, and providing feedback reports from students (Mobile Learning Unit, n.d.b) ${ }^{4}$.

The course is divided into six 'tutorials' (Box 1). Each tutorial concludes with an assessment comprising of five multiple-choice questions, and the course concludes with ten case studies that similarly have five related multiplechoice questions. Students receive a Certificate of Completion if they accomplish the assessment requirements and complete a short 'course evaluation'.

\footnotetext{
${ }^{1}$ A note on terminology. There are a variety of alternative terms for clinical supervisor, such as clinical educator and preceptor. We opted to use clinical supervisor throughout the report to align the term with the course's title.

${ }^{2}$ Royse (n.d.-b) distinguishes between 'light' and 'high touch' online learning. The former is defined as "An asynchronous learning mode with maximum automation and delivery via the computer system, requiring minimum teacher time."

${ }^{3}$ The Mobile Learning Unit was established by the University of Melbourne to connect academics and researchers with Healthcare Professionals through the delivery of Online Medical Courses.

${ }^{4}$ Student is used throughout the report; referring to a person who is engaged in studying.
} 


\section{Box 1. The structure of the Clinical Supervision Online course.}

1. What is clinical supervision?

2. A brief look at educational theories

3. Coaching clinical learners

4. Learner-centred clinical supervision

5. The challenging learner

6. Being a reflective supervisor

Ten case studies to consolidate learnings

It is suggested that the CSO course will take between six to ten hours of 'screen time' ${ }^{5}$. The course content can be accessed on mobile devices, its design intended to support mobile learning (Rice \& McKendree, 2014). The CSO course has been designed for students to solely interact with the course content; that is, interactions with other students or educators were consciously excluded.

Initially, the course content and the assessments were accessed on separate platforms; the Knowledge and Assessment Portals. At the end of August 2020, the course was made available via a new platform, the Student Learning Portal, with the course content and assessments available on the one platform.

\section{Overview of participation in the Clinical Supervision Online (CSO) course.}

With respect to the CSO course, the first student enrolled In June 2019, paying AUD\$350.00; a fee that has remained unchanged to the date of this evaluation. Eighteen months later, 204 students had enrolled on the course (Figure 1).

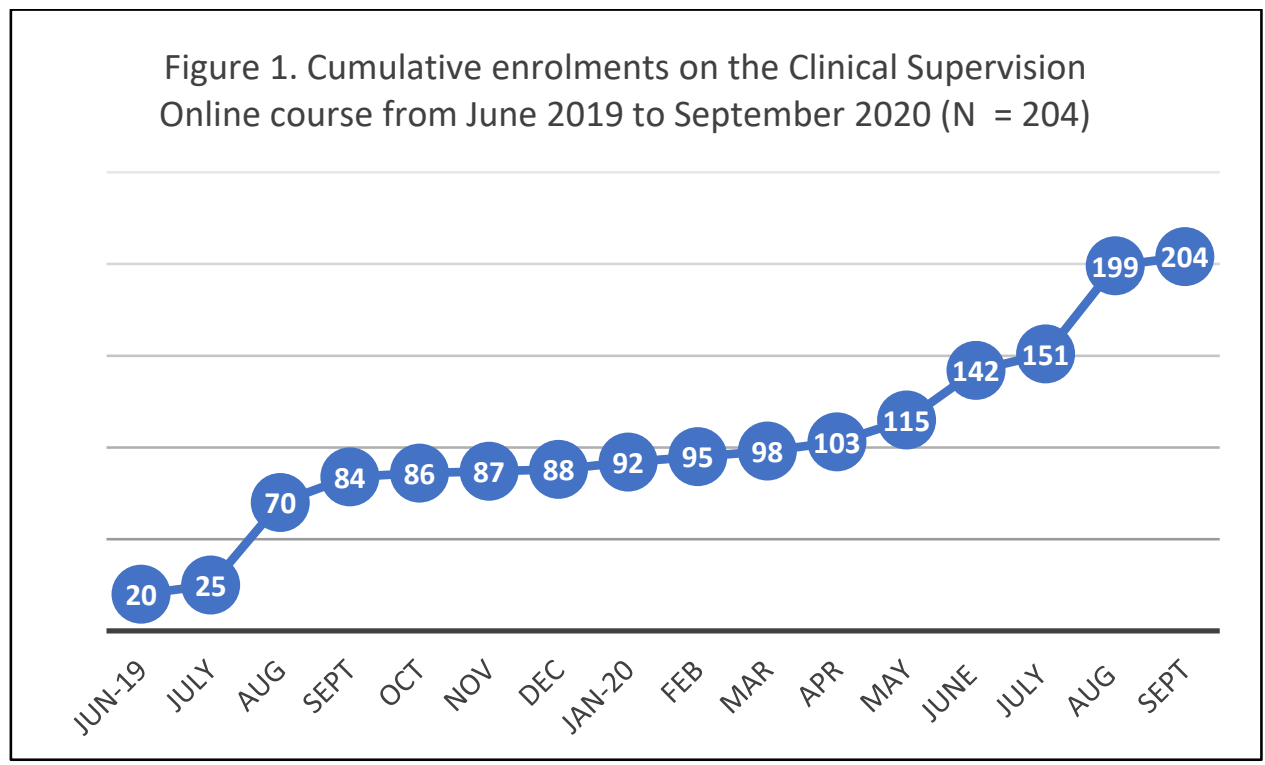

\footnotetext{
${ }^{5}$ The estimated 'screen time' is not listed as taking between 'six to ten hours', but these estimates come from two conflicting sources. The online Course Outline states, "Course completion requires approximately 10 hours", whilst the course brochure declares, "Course completion requires approximately six hours of screen time" (Mobile Learning Unit, n.d.-a)
} 


\section{Methods for the evaluation}




\section{Methodological challenges, decisions and limitations}

We held an initial scoping discussion with the Course Director to explore his motivations for undertaking the evaluation, which were expressed in terms of effectiveness, efficiency, and appropriateness; concepts that were explained respectively as a course that improves performance, being perceived as 'time well spent', with course content judged as relevant ${ }^{6}$.

Self-evidently, educators design learning activities that are intended to help students achieve a course's learning outcomes, adding to what students know and understand, and what they can do. The Course Director's interest in improved performance also shows a concern for the application of new knowledge and skills to clinical supervisors' workplaces. The transfer of learning to the workplace, at either the level of the individual learner or wider organisational practice are aspirational goals of professional development courses, like the CSO course. However, not only is such transfer of learning hard to demonstrate, but it also often requires a well-resourced longitudinal evaluation. As most evaluations are not well-funded, many rely on data that are easier to collect, such as satisfaction with a course; self-reported changes in knowledge, skills, and workplace behaviours; and pre- and post-test measures (Olanrewaju \& Thistlethwaite, 2013; Steinert et al., 2016; Steinert et al., 2006). As self-report data is routinely criticised for being unreliable (Davis et al., 2006), we thought that there was little to be gained by developing and administering an additional survey for students or interviewing a small sample of students who had completed the course about perceived changes in practice, as this data would add little to the existing course student postcompletion survey for a disproportionate amount of work.

The CSO course is a modest course with respect to engagement, requiring six to ten hours of study. Its primary focus is on increasing students' knowledge and understanding, but there are currently no associated valid assessments that 'measure' what students are expected to know and understand as a result of any learning. Additionally, there are no learning activities that are specifically designed to help students improve their skills, nor are there any explicit learning activities that require students to apply their knowledge and understanding to the workplace. If there is a 'theory of change' associated with the hoped for improvement in workplace performance, it is probably of the idealised selfdirected learner who is cognitively mature, possesses the abilities to transfer any learning in a meaningful way without the support of course tutors or workplace colleagues (Huber \& Hutchings, 2004; Kadirvelu \& Gurtu, 2015). In short, the responsibility lies solely with students to apply any new knowledge and understandings to their workplaces, which is possibly implicit in the course brochure, where it states, "Most learning will occur as participants apply new techniques to their daily work" (Mobile Learning Unit, n.d.-a, p.2).

The course design and retrospective nature of the evaluation precluded the use of more valid measures of changed practice, such as observations and audio-diaries, because introducing such data collection techniques would be confounding interventions in themselves, prompting students to apply the course content in their day-to-day work.

Some additional methodological challenges are posed by the fact that students can enrol in the course at any time. The passing of time is likely to impact on students' recollections of how they experienced the course, underscoring the unreliability of self-report data. We thought there was little to be gained from surveying or interviewing students who had completed the course months previously. Only being able to approach newly enrolled students to share their experiences risked turning the evaluation into a longitudinal project, exceeding our projected timeline for completing an evaluation ${ }^{7}$. (We subsequently discovered that students could take months to complete the course and a high percentage do not complete the course at all.)

The information that we were able to obtain about the course in initial scoping discussions shaped our methodological decisions and the final evaluation plan that we submitted to the Medical Education Human Ethics Advisory Group. As far as possible, we decided to use data that was already being collected by the Mobile Learning Unit. A postcompletion survey is embedded in the course's design, which collects data on students' perceptions of course

\footnotetext{
${ }^{6}$ Much of the CSO course content was re-worked from a longer, four-day face-to-face course. If the shorter, online course could achieve the same outcomes as the longer face-to-face course, this would be a more efficient use of time.

${ }^{7}$ Rolling enrolments, when student numbers are relatively small, potentially turns an evaluation that uses pre- and post-course measures of knowledge of clinical supervision into a longer-term project as one collects 'enough' respondents over time. Currently, a valid pre- and post-measure of knowledge about clinical supervision does not exist for the CSO course, so would have to be developed.
} 
administration and delivery (i.e. implementation), and course impact. As an online course we anticipated being able to request learning analytics data, which would inform how students were engaging with the course material.

\section{Approach to evaluation}

The evaluation plan was guided by Rossi, Lipsey and Freeman's (2004) approach to program evaluation. Figure 2 depicts their evaluation hierarchy, which encompasses the need for a program, its design, implementation, impact, and efficiency. As well as being able to touch on the Course Director's concerns, using their hierarchy allowed for a broader, multi-level evaluation of the CSO course.

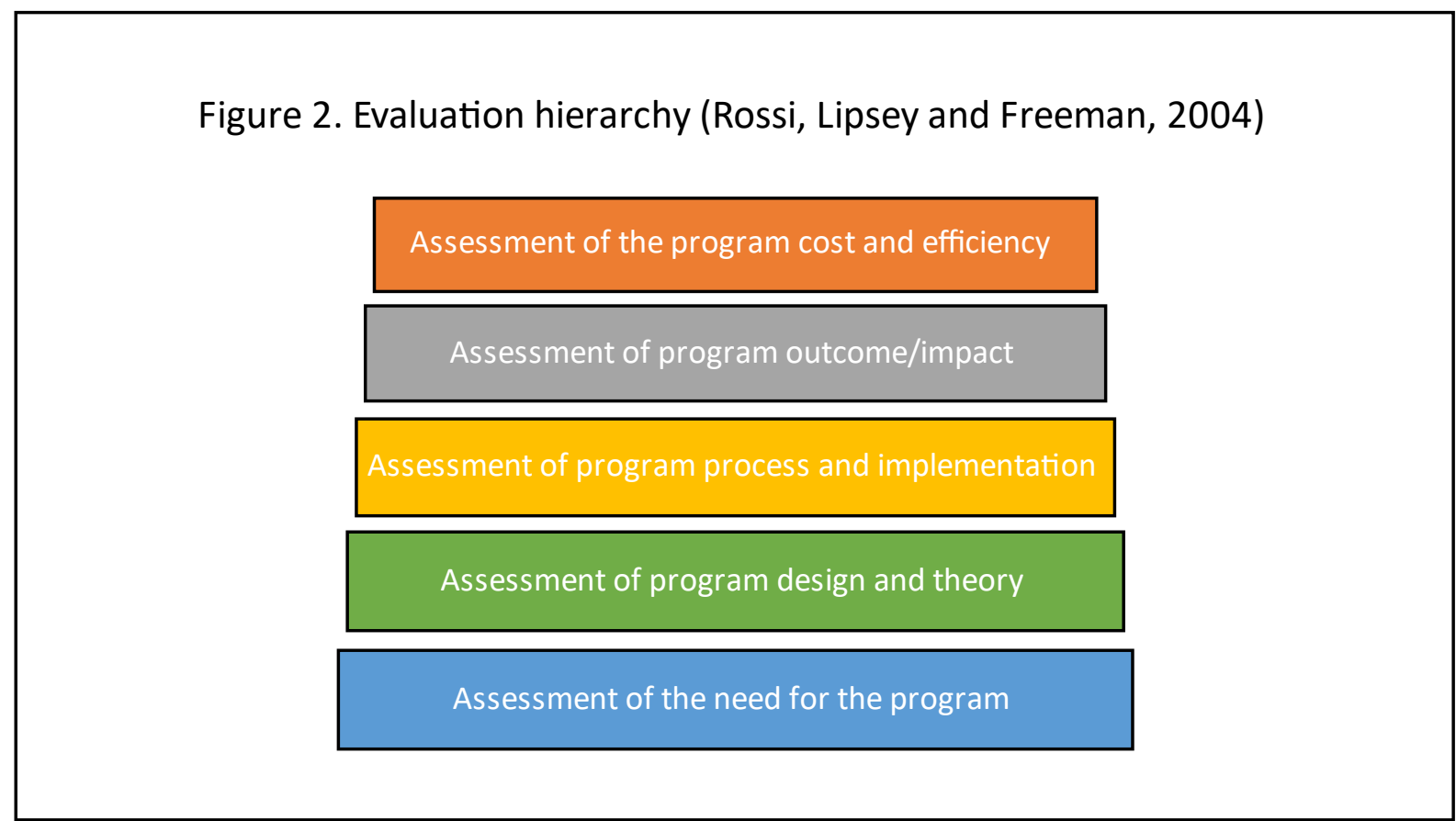

We identified five primary evaluation questions, one for each level of the evaluation hierarchy, framed with formative aspirations, primarily aimed with offering suggestions for improving the course's design, implementation, and impact. Such an orientation to improving teaching and learning activities is embedded in the University's 'ways of working' and engaging in continuous Quality Improvement is a particular expectation in medical education (Wong \& Headrick, 2020).

1. What is it about the problem of professional development for clinical supervisors that justified the development of the CSO course?

2. When compared to the standards for 'best practices' in online course development how well does the CSO course fare?

3. How well is the course operating?

4. To what extent does the CSO course effectively build students' knowledge and understanding of the of the role of the clinical supervisor?

5. What has been the University's return on investment?

We hope that answering these questions within the scope of the evaluation will provide benefits to both the Melbourne Medical School, in particular for the Department of Medical Education and the Mobile Learning Unit, and the wider community. As well as providing suggestions for improving the design of the CSO course, implementation and impact we hope that the findings and related commentary will inform conversations about the expectations placed on clinical supervisors, and both 'what' and 'how' professional development should be offered to them. 


\section{Data informing the evaluation of the Clinical Supervision Online (CSO) course}

We collected data from multiple sources to answer the five evaluation questions. We conducted semi-structured interviews with key informants involved in the initial design and development of the course and those involved in its ongoing implementation. Unfortunately, one member of the course development team was not contactable, having left the University's employment. In relation to financial issues, we deemed it more appropriate to ask written questions and receive written answers. We were given access to documents related to the course's development and read contemporary documents about the course; the latter being available on University webpages. As authors, we completed the CSO course and used a 'quality online course rubric' to evaluate the course design against the rubric's standards. We accessed deidentified data from the course student post-completion survey, which gathers quantitative and qualitative data about the course's implementation and impact. We accessed deidentified learning analytics data and deidentified data from the Customer Relationship Management (CRM) system. The former relates to the 'traces' that students leave behind in using the aforementioned Knowledge, Assessment, and Student Learning Portals, whilst the latter records students' personal details and interactions that they have with the University. Learning analytics data is typically used to improve learning, whilst CRM data is used to improve 'customer relationships'.

\section{A note on learning analytics data}

As 'outsiders', we knew nothing about the design of the course's analytics systems, but in planning the evaluation we assumed that because of the nature of the course that it would have a well-designed, integrated learning analytics function that would be able to capture, store, process, and analyse student data with relative ease (Nichols, 2020). We anticipated that these 'digital traces' of students' actual learner behaviours, would provide insights into how they engaged with different elements of the course (Rienties et al., 2017), from which we could make inferences about the success of the course's design, whether the learning activities were performing as expected, and student satisfaction.

After we had completed the course, we made written submissions to the Mobile Learning Unit with specific requests to access learning analytics data if it was available. For instance, how long students took to complete the course, answer the post-course cases, and questions about 'process analytics', capturing how students were carrying out tasks, such as watching videos and completing 'stop and think' exercises. Our assumptions about having a wellintegrated learning analytics function turned out to be erroneous; the course not being data-analytics driven (Nichols, 2020). Although we received some learning analytics data, it was significantly more limited than we anticipated.

\section{Data analysis}

The primary purpose of the semi-structured interviews was to get key informants' perspectives on the questions related to the different aspects of the evaluation hierarchy, not for the purpose of identifying themes, but for descriptive purposes; for example, to understand how the course came to be developed and was perceived to be operating on a day-to-day basis. For this reason, although the Interviews were audio-recorded, they were not transcribed. As the number of key informants was small, we opted not to use quotations, as a safeguard to help protect participant identities.

Documents, excluding the online course itself, broadly fell into two categories; older documents that were records of the course's development and contemporary documents presenting information about the course to potential students (Forster, 1994). We framed what people told us and what we read as "relatively uncontested data" (Stake, 1995, cited in Creswell, 2013, p.101), useful for providing context and 'telling' the course's story, and able to be triangulated with other data sources.

The Quality Online Course Initiative (QOCI) rubric (Illinois Online Network, 1998-2019) was used to evaluate the design of the CSO course ${ }^{8}$. The QOCl rubric is organised in seven categories, beneath which sit 27 standards and 97

\footnotetext{
${ }^{8} \mathrm{~A}$ number of 'best practice' rubrics have been developed to assist with the design and evaluation of online courses. In addition to the QOCI rubric (Illinois Online Network, 1998-2019), we also looked at the Quality Learning and Teaching (QLT) Instrument (The California State University, 2017), the Continuing and Professional Education Rubric ( $2^{\text {nd }}$ edition) from www.qualitymatters.org, and the University of Melbourne's Quality Assurance standards for learning design.
} 
'characteristics' or items. Each item is rated on a four-point scale: non-existent, developing, meets, or exceeds, with a 'not applicable' option also available (see Table 1).

Table 1. The QOCI rubric levels of performance and criteria (Illinois Online Network, 1998-2019).

\begin{tabular}{|c|l|}
\hline Level of Performance & \multicolumn{1}{c|}{ Criteria } \\
\hline Non-Existent & $\begin{array}{l}\text { Not Present, but should be, based on course design and content, or present, but not } \\
\text { appropriate for this course. }\end{array}$ \\
\hline Developing & $\begin{array}{l}\text { Some evidence of this criterion, but it needs to be presented more clearly or better } \\
\text { developed. }\end{array}$ \\
\hline Meets & $\begin{array}{l}\text { Evidence of this criterion is clear and is appropriate for this course. More could } \\
\text { possibly be added. }\end{array}$ \\
\hline Exceeds & $\begin{array}{l}\text { Evidence of this criterion is clear, appropriate for this course, and demonstrates best } \\
\text { practices in a manner that models its use. }\end{array}$ \\
\hline Not applicable & Not applicable based on course design and content. \\
\hline
\end{tabular}

TC and BV completed the CSO course and used the QOCI rubric to arrive at independent ratings. The 'not applicable' option was assigned when it was judged that the course had been consciously designed to exclude particular design characteristics. For example, an item in the Communication, Interaction, and Collaboration category is 'Learning activities and other opportunities are developed to foster Student-Instructor communication and/or collaboration'. As the course's 'light touch' deliberately excluded student-instructor interactions, this item was rated 'not applicable'. BV and TC met to compare ratings and reach a consensus rating where there were initial differences. Evidence in the form of type-written notes, justifications for each rating, were synthesised into an analytic commentary for the rubric's seven major categories, which are reported in section entitled The Design of the Course.

Individual data from the 14 Likert-items in the course student post-completion survey were aggregated and descriptive statistics were used to summarise basic information about the 'variables' of interest in the respective questions. For reporting purposes, we separated the items related to the administration and delivery of the course from those on impact.

The qualitative data from the related open-ended text boxes was thin, not worthy of a rigorous qualitative analysis (LaDonna et al., 2018). Drawing on principles of content analysis, respondents' responses were clustered into broad categories.

As stated above, the available learning analytics data was limited, as the analytics system had not been designed to answer a priori questions about students' behaviours (Mangaroska \& Giannakos, 2019; Nichols, 2020). We typically received raw data in Excel spreadsheets that required further processing in order to be suitable for high-level analysis. A first stage was to determine whether there was anything useful in the data, and if we thought there was, to determine a specific analytic strategy. We have integrated learning analytics data into the sections that follow, with accompanying details of the respective analytic approaches.

\section{Ethical approval}

Ethical approval was given by The University of Melbourne's Medical Education Human Ethics Advisory Group (Reference number 2057555.1). 


\section{Findings of the evaluation}




\section{The need for the course}

In this section, the 'need' for the course is discussed in two contrasting ways; initially as a 'training need' and subsequently as a 'financial' one'. Thinking about the CSO course as a response to a 'training need' reflects conventional thinking; that is, there is a 'problem' about the performance of clinical supervisors and the solution is a professional development activity that will either improve their performance or bring it up to the required standard (Boydell \& Leary, 1996). Positioning the University as a commercial entity allows the success of the course to be judged against a different set of economic criteria (Enders, n.d.). Our aim in this section is not to resolve any issues about the need for the CSO course, but to provide foundational context to inform forthcoming discussion.

\section{Need as 'training need'}

"A proposition is said to be certain when it is indubitable" (Honderich, 1995, p.129).

The proposition that clinicians need to be formally prepared to become clinical supervisors - to be taught how to teach - is (probably) beyond doubt. Libraries are full of books and papers about effectively equipping clinicians for this role in order to improve outcomes for the learner, offer improved patient care and contribute to the development of a skilled and sustainable health workforce. Education and training providers offer numerous short- and long-term courses to this end. In-house, short-term offerings are similarly made available to clinical staff by health and social care organisations. That clinicians 'need' professional development of some sort in order to be effective clinical supervisors will not be disputed here, but given that people and organisations have seen the 'solution' to clinical supervisors 'training needs' differently, it is pertinent to ask, 'What exactly are the 'training needs' of effective clinical supervisors and how might they be effectively met'?

Diverse professional development 'solutions' suggest that that the answers to these questions are uncertain. Health Workforce Australia (2010) recognised the lack of consistency in the education of health professionals resulting from such uncertainty and proposed a nationally uniform approach to the education of clinical supervisors within all health professions. Health Workforce Australia established the Clinical Supervisor Support Program, subsequently releasing the National Clinical Supervision Competency Resource (Health Workforce Australia, 2014), which described the core competency requirements of clinical supervisors in any health discipline. The dissolution of Health Workforce Australia in 2014 meant that recommended systems-level changes were not followed-through. As a consequence, there remain enduring differences in conceptualising the role of the clinical supervisor and a mélange of professional development opportunities on offer to clinical supervisors, of which the CSO course is but one.

Given that the CSO course is a particular 'solution' to the problem of clinical supervisors' professional development, we made a targeted search of the academic literature for similar online courses to understand how they had been structured in comparison with the CSO course. Taken as a whole, the reviewed studies did not adhere to any standardised guidelines for reporting educational interventions, such as the Standards for Quality Improvement Reporting Excellence (Ogrinc et al., 2019), which made extracting common information about the educational designs problematic. Table 2 provides brief descriptions of the reviewed courses, summarised from the available information, which allows basic comparisons to be made. 
Clinical Supervision Online course offered by the Melbourne Medical School.
Fee-paying, online 'light touch' program for clinical supervisors who teach and/or supervise learners at any level. Six 'tutorials' and 10 end-of-course case studies. Each tutorial concludes with an assessment comprising of five multiplechoice questions. It is suggested that the course will take between six to ten hours of 'screen time'. Students are awarded a Certificate of Completion.

Five self-directed modules; four core and one course specific. Participants were rural and remote pharmacy preceptors, recruited from four Australian universities in three states. Estimated 20 hours to complete the course. People reported $<10$ to $20-30$ hours to complete the course.
Taylor et al. (2007) Participant views of an on-line program supporting rural pharmacy preceptors.
Eight stand-alone modules, completed in any order, designed for nurses to take on a clinical supervisor role in the USA. Free, self-paced, accredited, online program. Interactive PowerPoint, interactive quizzes, video vignettes, organisational ideas, articles, and 'other' resources.
Dunker (2014) Development and preliminary testing of an on-line continuing education program for adjunct clinical nursing faculty.
One module addressing four 'areas', using video-vignettes, instructional slides, adaptive learning, and a wiki. Physical Therapy Clinical Instructors in the USA.
Kyeong-Ju \& Engelhard (2014) Using the Constructivist Tridimensional Design Model for online Continuing Education for Health Care Facility.

Larsen \& Zahner (2011) The Impact of Web-delivered Education on Preceptor Role Self-Efficacy and Knowledge in Public Health Nurses.

Zahner (2006). Partnerships for Learning PopulationBased Public Health Nursing: Web-Delivered Continuing Education for Public Health Nurse Preceptors.

for clinical supervision.

Monash Health (2013) Clinical supervision support across contexts (ClinSSAC).

Tai et al. (2016) Clinical supervision training across contexts.

Myrick et al. (2011) Preceptor/mentor education: A world of possibilities through e-learning technology.

Weston (2018) The Clinical Instructor Program.
Course for nurse preceptors in USA entitled, 'Partnerships for Learning Community Health Nursing'. Nine modules, for which participants were given one contact hour of Continuing Education credit for each module. (Average completion time for each module was 35 minutes.) Includes video-vignettes, links to other resources, and four multiple-choice quiz questions after each module. Some participants completed the modules in a single sitting, others took 3-4 weeks. A Continuing Education certificate was awarded on completion of the course.

Online course for nurses in Northern Ireland. Derived from a one-day workshop. Mean time spent completing the course was two hours (range 1-4 hours). Interactive learning activities and theoretical content. Observation of a supervisory session was replaced by reflective activity after the pilot. A self-test was also added.

Free cross-disciplinary course from Australia, with blended and online versions of the program. Core clinical supervision module; 15 profession-specific modules; 10 context-specific modules, and two education modality modules.

Canadian study including supervisors in other countries. Eleven modules, including synchronous and asynchronous discussions. Completed as a fivemonth project. Participants received a Certificate of Attendance.

Program for nurse clinicians from the USA. Six online modules, using video-clips, formative quizzing, and active learning. Participants reported completing the modules in 20 hours, or completing the modules over 3 months. 
The eight reviewed courses were from Australia, Canada, Northern Ireland, and the United States of America. Six of the courses were for particular disciplines (Nursing, Pharmacy, and Physical Therapy), whilst the remaining two were designed for any health discipline. The courses all reported modular-like structures, ranging from one to 11 modules, taking between one and thirty hours to complete. (The generic courses had core content, which was supplemented by specific discipline content.) Like the CSO course, some courses were designed solely for interactions between students and the content, whilst others also included interactions between students and tutors, and students and other students.

Drivers for developing these courses were typically pragmatic, such as overcoming geographical constraints or the challenges of releasing staff from their day-to-day jobs to attend face-to-face training sessions (McColgan \& Rice, 2012), keying into dominant discourses of 'access', 'convenience' and 'flexibility' that pervade discussions about the use of digital technologies for teaching and learning (Phillips, 2006). Newer courses, such as the CSO course have also been developed to support mobile learning, that is, the course content can be accessed on mobile devices (Rice \& McKendree, 2014). As well as being 'accessible', 'flexible' and 'convenient', mobile learning may also reflect certain assumptions about the way people wish to learn; in particular that they wish to learn in short, five- to ten-minute blocks of learning (Royse, n.d.-a).

Authors provided variable detail about module content. Table 3 provides a broad-brush approach to the indicative course content, based on content titles or other similar descriptions. As above, without greater detail about learning outcomes, content, and learning activities, only the most basic comparisons can be made. Some topics feature prominently, such as, an introduction to clinical supervision, assessing clinical performance, and supervising the challenging or unsafe learner. Other topics are named less frequently, such as, cultural competence, learning styles, medication administration, and listening skills, although these topics may sit beneath other headings. 
Table 3. Course content: Comparison of the Clinical Supervision Online course to broadly similar courses.

\begin{tabular}{|c|c|c|c|c|c|c|c|c|c|}
\hline 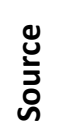 & $\begin{array}{c}\text { Clinical Supervision } \\
\text { Online course }\end{array}$ & $\begin{array}{l}\text { Dalton et al. } \\
\text { (2007); Taylor et } \\
\text { al. (2007) }\end{array}$ & Dunker (2014) & $\begin{array}{l}\text { Kyeong-Ju and } \\
\text { Engelhard (2014) }\end{array}$ & $\begin{array}{c}\text { Larsen and Zahner } \\
\text { (2011); Zahner } \\
\text { (2006) }\end{array}$ & $\begin{array}{c}\text { McColgan and Rice } \\
\text { (2012) }\end{array}$ & $\begin{array}{l}\text { Monash Health } \\
\text { (2013); Tai et al. } \\
\text { (2016) }\end{array}$ & $\begin{array}{l}\text { Myrick et al. } \\
\text { (2011) }\end{array}$ & Weston (2018) \\
\hline 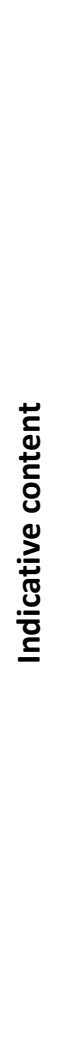 & $\begin{array}{l}\text { What is clinical } \\
\text { supervision? } \\
\text { A brief look at } \\
\text { educational } \\
\text { theories } \\
\text { Coaching clinical } \\
\text { learners } \\
\text { Learner-centred } \\
\text { clinical supervision } \\
\text { The challenging } \\
\text { learner } \\
\text { Being a reflective } \\
\text { supervisor }\end{array}$ & $\begin{array}{l}\text { Introduction to } \\
\text { preceptor } \\
\text { education } \\
\text { Focus on the } \\
\text { Student } \\
\text { Focus on the } \\
\text { Preceptor } \\
\text { Challenges and } \\
\text { problems in } \\
\text { supervision } \\
\text { Putting the theory } \\
\text { to work }\end{array}$ & $\begin{array}{l}\text { Cultural } \\
\text { competency in } \\
\text { nursing education } \\
\text { How to measure } \\
\text { clinical } \\
\text { competency } \\
\text { How to give clinical } \\
\text { evaluation } \\
\text { Safety with } \\
\text { medication } \\
\text { administration } \\
\text { Stimulating critical } \\
\text { thinking } \\
\text { Curriculum design } \\
\text { Reflection of } \\
\text { novice clinical } \\
\text { faculty }\end{array}$ & $\begin{array}{l}\text { Establishing the } \\
\text { groundwork for } \\
\text { clinical } \\
\text { experiences } \\
\text { Identifying } \\
\text { interventions to } \\
\text { prevent adverse } \\
\text { situations } \\
\text { Implementing } \\
\text { enhanced listening } \\
\text { skills } \\
\text { Increasing } \\
\text { awareness of } \\
\text { professional } \\
\text { behaviours }\end{array}$ & $\begin{array}{l}\text { The role of the } \\
\text { preceptor } \\
\text { Course } \\
\text { expectations } \\
\text { Policies and } \\
\text { procedures } \\
\text { Learning } \\
\text { population- } \\
\text { focused public } \\
\text { health nursing } \\
\text { Learning styles and } \\
\text { teaching strategies } \\
\text { Learning critical } \\
\text { thinking } \\
\text { Learning cultural } \\
\text { competence in } \\
\text { community health } \\
\text { nursing } \\
\text { Addressing difficult } \\
\text { situations } \\
\text { Providing feedback } \\
\text { and evaluation }\end{array}$ & No details given. & $\begin{array}{l}\text { Introduction to } \\
\text { clinical supervision } \\
\text { Self-assessment } \\
\text { How students learn } \\
\text { Facilitating } \\
\text { learning } \\
\text { Giving effective } \\
\text { feedback } \\
\text { Clinical assessment } \\
\text { Managing } \\
\text { underperformance }\end{array}$ & $\begin{array}{l}\text { How to engage } \\
\text { effectively in the } \\
\text { evaluation process } \\
\text { The timing and } \\
\text { relevancy of giving } \\
\text { feedback } \\
\text { The importance of } \\
\text { understanding the } \\
\text { different teaching } \\
\text { and learning styles } \\
\text { when working with } \\
\text { students } \\
\text { Cultural } \\
\text { competence and } \\
\text { safety } \\
\text { Precepting the } \\
\text { unsafe student }\end{array}$ & $\begin{array}{l}\text { Philosophical } \\
\text { foundations of } \\
\text { clinical teaching } \\
\text { and learning } \\
\text { Orienting students } \\
\text { to the clinical } \\
\text { setting } \\
\text { Curriculum/course } \\
\text { overview: The } \\
\text { context for clinical } \\
\text { teaching. } \\
\text { Making clinical } \\
\text { learning } \\
\text { assignments } \\
\text { Clinical teaching } \\
\text { strategies } \\
\text { Evaluation of } \\
\text { clinical } \\
\text { performance }\end{array}$ \\
\hline
\end{tabular}


Even such a cursory review of online courses illustrates the aforementioned variability in what course designers identify as needing to be taught, and to what level of complexity. This is not surprising. Although online learning is likely to take a team-based approach to its development, involving partnerships between academics and learning activity designers (Nichols, 2020), without broader agreement about what clinical supervisors need to know and be able to do, the academics, as content experts, have considerable freedom to set their own boundaries. This freedom is exacerbated when courses do not lead to a formally recognised qualification, as is the case for the CSO program.

In this regard, it is useful to compare the estimated time taken to complete the CSO course (six to ten hours) and the reviewed courses (one to thirty hours) with the 'volume of learning' required to obtain a qualification under the Australian Qualifications Framework (2013). Expressed in equivalent full-time years, 'volume of learning' is the "notional duration of all activities required for the achievement of the learning outcomes specified for a particular AQF qualification type" (p.11). Levels within the Australian Qualifications Framework define the relative complexity and depth of achievement. Even though there is a debate to be had about the depth of achievement required of an effective clinical supervisor, the volume of learning for a Certificate IV, Graduate Certificate, and Graduate Diploma is $0.5-2$ years, $0.5-1$ year, and $1-2$ years respectively; significantly different from the duration of these online courses.

From this perspective, is the CSO course a reasonable solution to meeting the training needs of 'clinicians who teach and/or supervise learners at any level'? Can a generic, 'light touch' online course of six- to ten-hours duration, employing only interactions between students and the designed content achieve the depth of achievement implied in the course aims and learning outcomes, of giving clinicians the understanding and skills to create learning environments within which learners can thrive?

\section{Need as an economic imperative}

The Clinical Supervisor Online course sits somewhat outside the core post-secondary-school education remit of the University (Nichols, 2020), being a short-course, professional development activity, leading solely to a Certificate of Completion. There is nothing wrong with the University providing such courses, but it does bring in to focus a second way of thinking about the purpose of a university and the 'need' for the course. As an economic entity, an offering like the CSO course is a way of making money for the University (Nichols, 2020). Addressing the 'need' for the course from this perspective foreshadows business-related elements of the evaluation, such as market analysis and return on investment.

Royse (n.d.-a) identifies 'market evaluation' as an important stage in the life cycle of an online learning course to ensure that it has potential and is sustainable. An initial 'market analysis' estimated the market size for the course as 19,370 individuals; five per cent of a larger pool of 387,390 clinicians in medicine, allied health and nursing (Mobile Learning Unit, 2018) ${ }^{9}$. A related 'competitor analysis', undertaken by the Mobile Learning Unit, listed four 'current competitors' in the project proposal document (Table 4).

\footnotetext{
${ }^{9}$ Royse (n.d.-a) states that between one and five percent of a total market is ever likely to do a course. A one percent estimate would be 3,874 students.
} 


\begin{tabular}{|l|l|}
\hline Current competitors & Cost \\
\hline $\begin{array}{l}\text { People in Health } \\
\text { Clinical Supervision Support program } \\
\text { One day face to face workshop across Australia }\end{array}$ & Free \\
\hline $\begin{array}{l}\text { Health Education and Training } \\
\text { Clinical Supervision Support for Allied Health Professionals } \\
\text { Online } 1 \text { hour }\end{array}$ & Free \\
\hline $\begin{array}{l}\text { Online Clinical Supervision Services } \\
\text { Fundamentals of Clinical Supervision E-Learning Course } \\
\text { Allied health, nursing and welfare professionals }\end{array}$ & \$325 \\
\hline $\begin{array}{l}\text { University of East Anglia } \\
\text { Online Clinical Supervision Course } \\
2 \text { weeks, } 4 \text { hours per week }\end{array}$ & Free \\
\hline
\end{tabular}

${ }^{a}$ This online course is not aimed at educators of clinical trainees, but clinical supervision in a different sense.

A market analysis also helps in setting a 'price point' for a course. The project proposal listed a suggested course fee of $\$ 500.00$, which was reduced to $\$ 350.00$ at the course's launch. If all five per cent of the larger pool of clinicians completed the course, it would generate a significant income for the University of $\$ 6.75$ million.

\section{Linking conceptualisations of 'need' to the evaluation hierarchy}

Providing this foundational context draws attention to how the levels in the Rossi et al (2004) evaluation hierarchy are related. Considering whether the CSO course is good solution to the 'problem' of clinical supervisors' performance is informed by considering issues of design, implementation and impact. From a commercial perspective, gathering financial data will assist in making a judgement whether the course has realised a good 'return on investment' for the University.

\section{The design of the course}

The QOCI rubric (IIlinois Online Network, 1998-2019) was used to assess the design of the CSO course that was delivered via the original Knowledge and Assessment Portals. In essence, the same course was transferred to a 'single' Student Learning Portal in August 2020, with minimal changes. The comments that follow apply equally to either mode of delivery.

The QOCI rubric provides quality standards for online courses against which the CSO course can be assessed. Table 1 shows the four levels of performance. Of the 97 items that were independently rated, there were only nine discrepancies: a $91 \%$ agreement between the two raters. Thirty-three items were identified as 'not applicable'; based on raters' assessment of the course design. This high figure, thirty-four per cent of the total number of items, should not be interpreted as a negative judgement about the appropriateness of the $\mathrm{QOCl}$ rubric. Rather, the related features of best practice online design identified on the QOCI rubric were deliberately excluded from the CSO course's design; raising judicious questions as to whether these exclusions were reasoned and reasonable.

Of the remaining 64 items, the level of performance was rated as 'meets' for 44 items; 'exceeds' for one item; 'developing' for 13 items; and, 'non-existent' for six items (Table 5). In this section, suggestions for improving the course are based on the 64 'applicable' items, relevant for the 'light touch' design. 
Table 5. Number of items on the QOCI rubric assigned to each performance level by category for the CSO course.

\begin{tabular}{|c|c|c|c|c|c|}
\hline $\begin{array}{l}\text { Level of performance } \\
\text { Category }\end{array}$ & Non-existent & Developing & Meets & Exceeds & $\begin{array}{c}\text { Not } \\
\text { applicable }\end{array}$ \\
\hline Instructional design $(n=23)$ & 1 & 4 & 10 & & 8 \\
\hline $\begin{array}{l}\text { Communication, interaction, } \\
\text { and collaboration }(n=11)\end{array}$ & & & & 1 & 10 \\
\hline $\begin{array}{l}\text { Student evaluation and } \\
\text { assessment }(n=22)\end{array}$ & 1 & 2 & 11 & & 8 \\
\hline $\begin{array}{l}\text { Learner support and resources } \\
(n=8)\end{array}$ & 2 & & 4 & & 2 \\
\hline $\begin{array}{l}\text { Instructional materials and } \\
\text { technologies }(n=14)\end{array}$ & & 1 & 12 & & 1 \\
\hline Accessibility $(n=16)$ & 2 & 3 & 7 & & 4 \\
\hline Course evaluation $(n=3)$ & & 3 & & & \\
\hline Total $(n=97)$ & 6 & 13 & 44 & 1 & 33 \\
\hline
\end{tabular}

In the sections that follow an analytic commentary is provided, organised according to the QOCl rubric's seven major categories. Each section is a synthesis of the key insights, rather than an item-by-item account. Appendix A provides the individual ratings for each item.

\section{Instructional design}

Instructional design refers to the overall approach to designing the course in a way that enables the students to acquire the intended knowledge and skills, using a variety of instructional methods (Illinois Online Network, 19982019). Of the 23 items rated in this category, 10 were rated as 'meets'; four as 'developing'; and one as 'non-existent. Eight items were judged as 'not applicable' for the course design.

The course has a clear landing page, with well-signposted icons for the eight course elements (a study guide, six tutorials and the case studies $)^{10}$. The six tutorials have a common structure, which facilitates 'learner familiarity'. Each tutorial lists a 'Table of Contents' and learning outcomes at the top of each tutorial but does not list the learning activities to be completed in each tutoria| ${ }^{11}$. Overarching course outcomes are only listed on a University webpage and in the course brochure.

The course is logically sequenced, with clear signposting to content to be covered in later tutorials or to content previously covered. Students can undertake the tutorials in any sequence and complete them according to their own timelines (i.e., it is self-paced). The tutorials have a repetitive internal structure, where narrative is followed by an activity. Figure 3 uses a series of icons to illustrate the interactive features in Tutorial $1^{12}$.

\footnotetext{
${ }^{10}$ On the newer Student Learning Portal, there are nine rather than eight 'tutorials'. An additional 'Where to next' tutorial has been created, which is merely re-packed content from the final tutorial in the earlier version on the Knowledge Portal. The newer course landing page is more sophisticated, making it easier to navigate to specific sections of any tutorial.

${ }^{11}$ The landing page for the new Student Learning Portals allows students to navigate directly to quizzes in any tutorial.

${ }^{12}$ Depicting the content in this way took inspiration from Cirigliano, Guthrie, and Pusic (2020).
} 
Figure 3. Map of Tutorial 1: What is clinical supervision?- organization of interactive features

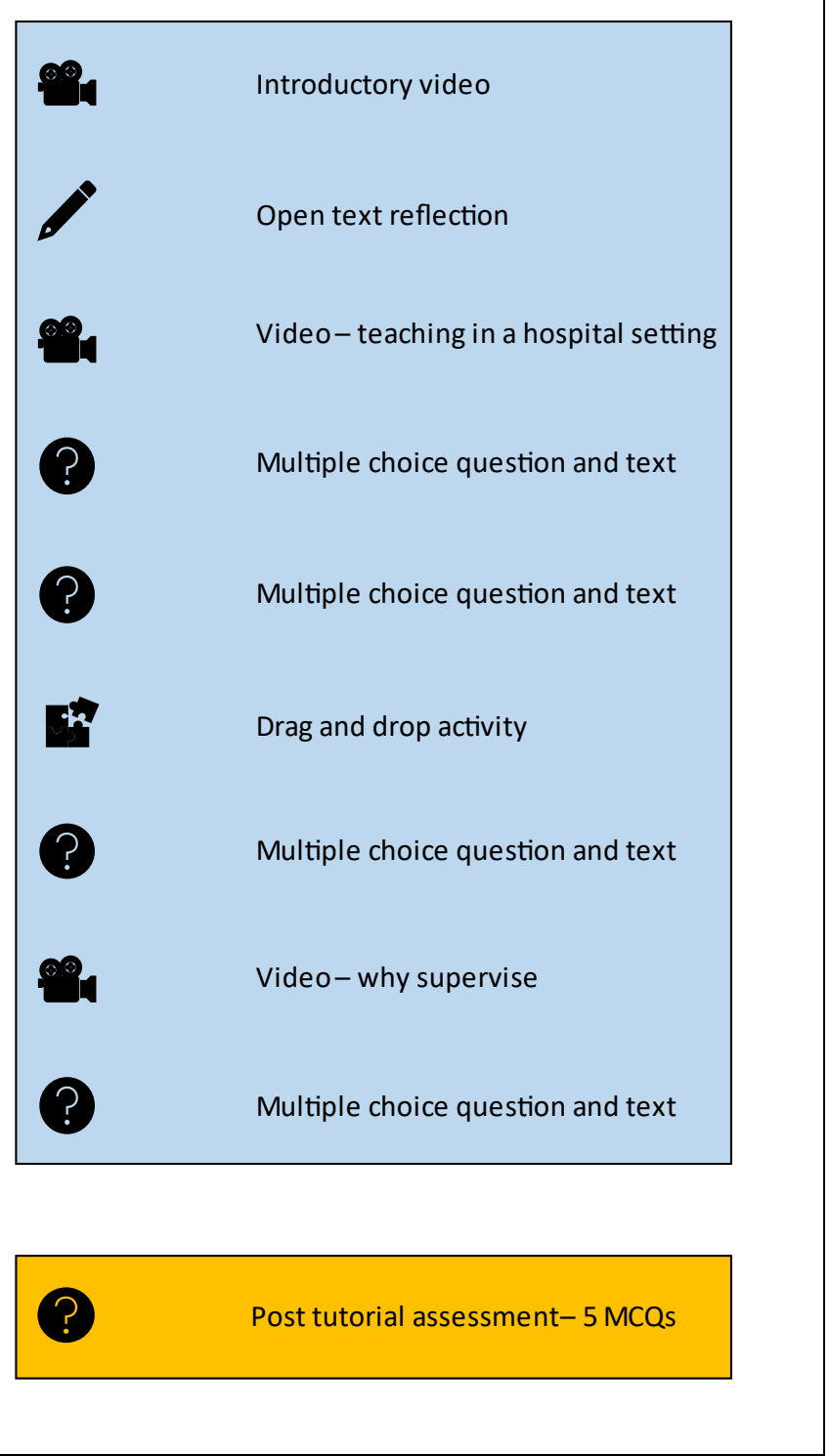

The 'light touch' design incorporates three components in each tutorial; knowledge, reinforcement, and assessment (Royse, n.d.-b), with the use of each being crucial to how students interact with the content. Each tutorial contains interactive content to support learning, such as self-reflective questions and drag-and-drop activities, which are designed to complement the core text. There is a potential danger that the repetitive structure may be perceived as monotonous by some students if the course is completed within a short time-frame. The purposes of the activities are chiefly implicit, which may become clearer once they have been completed.

A description of the course is available on a University webpage and a downloadable brochure. The estimated time to complete the course is not consistent across the course materials. As a fully online, uni-modal course, all the course materials are available online; the instructional content, assessments, and online support. Acknowledgements related to some images may be missing. The first tutorial has a short introductory video, which also introduces the Course Director. The use of video-files is a strong design feature. They are variable in quality, but are used with a clear purpose. 'Talking head' videos from the Course Director appear throughout the course and interviews with clinical supervisors introduce practice wisdom. The role play videos might be viewed by some students as 'staged' rather than authentic. The movie-clips are of variable quality and require more effort on behalf of the student to link to the course content. As a 'light touch' course, it is intended to be completed without any contact with educators ('a supporting 
academic team' $)^{13}$. Requests for support are made via a generic email address monitored by employees of the Mobile Learning Unit.

\section{Recognition}

There is no formal award for completing the course, but a Certificate of Completion. Clear guidance states what students must complete to obtain the Certificate. The primary way in which students demonstrate their knowledge is through the post-tutorial assessments and a series of ten case studies in the final tutorial. The questions are all Multiple-Choice Questions, which are automatically 'marked'. The 'light touch' design consciously excludes assessment options that require human assessors. The limited repertoire of in-tutorial activities provides other opportunities to demonstrate learning (e.g., drag and drop activities) and engage in reflective tasks (i.e., to write about experiential knowledge). With no educator or student contact, students receive no feedback about their written answers. Technical requirements (e.g., connection speeds) could be more clearly indicated and there are no details about any technical competencies required by the students.

Suggestions for improving the existing course:

- Signpost the overarching course outcomes in the online course, not solely on the webpage and course brochure, and indicate how tutorial outcomes link to them.

- Articulate the purpose of all learning activities.

- Provide a consistent estimate of time to complete the course.

- State the technical competencies required of students.

- Provide clearer details about technical requirements required to access the course, and ensure that data intensive resources are accessible across a variety of platforms, and accessible with slower internet connections.

- Confirm that all images that need to be acknowledged, are acknowledged.

\section{Communication, interaction, and collaboration}

Communication, interaction, and collaboration focuses on how the design of the course, any assignments, and technology support interactions between the content, other students, and educators (Illinois Online Network, 19982019) ${ }^{14}$. Of the 11 items rated in this category, one was rated as 'exceeds' and the remainder were judged as 'not applicable', as the CSO course's 'light touch' design deliberately excludes interactions between other students and educators, and therefore also excludes, for example, the related need to set up online forums and establish rules for interacting with others.

The CSO course is exclusively content-interactive in nature, and was judged to demonstrate some excellent features in this regard. Each tutorial contained multiple short-pieces of written material, immediately followed by interactive content to support learning, such as drag-and-drop activities and case studies. A key question, whether the course is 'weaker' for only using one type of interaction is discussed below.

\footnotetext{
${ }^{13}$ The Course Director invites students to contact him via a generic email. No students had taken-up the offer.

14 These are the three types of interaction described by Moore (1989).
} 


\section{Student evaluation and assessment}

Student evaluation and assessment refers to the processes used to determine students' achievement, including the quality of their work and the allocation of any grades (Illinois Online Network, 1998-2019). Of the 22 items rated in this category, 11 were rated as 'meets'; two as 'developing'; and one as 'non-existent. Eight items were judged as 'not applicable' for the course design.

The course's assessment goals are communicated to students in a number of places. The course brochure, for example states that, "Assessment is submission of the eLearning self-assessments contained within the course, as well as submission of 10 case studies. A Certificate of Completion is provided upon satisfactorily completing the course" (Mobile Learning Unit, n.d.-a). It should be clear to students at the point of enrolment what they have to do, what feedback they will get, and what 'award' they will receive.

Assessments are frequent; each tutorial concluding with a post-tutorial assessment. The assessment methods are solely Multiple-Choice Questions (MCQs), which assess low-level knowledge (Bone \& Prosser, 2020). MCQs are an efficient way of providing immediate feedback to students, marked as either 'right' or 'wrong', although text in the course's Introduction suggests greater nuance, "Clinical supervision is a field where there are not many "absolute facts" that lend themselves to multiple choice questions". Such nuance gives leave for students to dispute the given answers; although the absence of educators and students precludes immediate, direct discussion.

Although efficient in the 'light touch' design, MCQs cannot determine whether the course's learning outcomes have been met. This creates a mismatch between the stated learning outcomes and the assessment tools used. The fact that the CSO course is non-award bearing testifies to the view that these assessments are not a valid assessment of the learning outcomes. Academic integrity is maintained by merely offering a Certificate of Completion. Different assessment methods would be required to demonstrate that the learning outcomes have been achieved, which would move the course away from its 'light touch' design.

Students can complete the assessments in their own time. The course handbook gives scant generic information about the assessment 'pass mark' and students' ability to re-take the assessments, nor the time required to undertake the assessments. It would be helpful to both repeat the requirements at the start of the assessments and provide more granular information (e.g., how many questions one needs to get correct and how many attempts are permitted) or highlight the formative nature of the assessments as a strategy to reinforce and consolidate learning.

The post-tutorial self-assessments and case studies were initially on a separate Assessment Portal, which shows both the status of assessments ('not started', 'in progress', or 'completed') and 'results' as a percentage. Students are required to answer four out of five answers correctly (80\%) on each assessment and can have up to three re-takes. The dashboard tracks students' progress through the course content and if students have completed all the assessments, then it is assumed that they have covered the course content.

Within the tutorials are a number of assessment-like activities, which are more varied, but are not considered in awarding the Certificate of Completion. The in-tutorial activities similarly provide immediate feedback once an answer has been submitted, such as an explanation or summary (Box 2). Some activities ask for 'free text'. These responses are not monitored, so no mechanism exists for judging the quality, and students receive no feedback or extra 'credit' for a comprehensive, insightful response. 
Box 2. 'Stop and Think' exercise from Tutorial 3: No-fuss educational theories

\section{Stop and Think}

Think of clinicians you have known in your career whom you admire. What qualities make you consider them a "master" of their craft rather than just an expert?

Write your explanation in the box below.

\section{Done}

\section{Solution/summary}

Respondents generally refer to colleagues whom they consider to be "masters" as those who are able to address unprecedented situations and achieve the best possible outcome for that person in that situation at that time. In other words, they are able to take calculated risks, when appropriate, to achieve what's needed in a given circumstance.

Being an "expert" means the job is done precisely and properly each time. Being able to appropriately "deviate from the script" to achieve an outcome is the mark of a "master". A "master" mixes solid expertise with the wise intuition that only comes from experience.

Thousands of years ago, Aristotle captured this concept as "phronesis"; the ability of the master to think and act prudently1. Being able to perform a task with the added benefit of their experience, wisdom and ethical thinking in deciding whether to and, if so, exactly how to go about it. In other words, to add wisdom to knowledge. While our novice learners might bring ample knowledge from their classroom, they lack practical experience to translate

\section{Suggestions for improving the existing course:}

- Consider to what extent it is possible to include assessments that can measure the stated course outcomes without jeopardising the 'light touch' design.

- Provide clearer guidance about the assessment 'pass mark' and the number of re-takes permitted. 


\section{Learner support and resources}

Learner support and resources addresses the institutional, academic, and technical resources that are available to learners (Illinois Online Network, 1998-2019). Of the eight items rated in this category, four were rated as 'meets', two as 'non-existent' and two as 'not applicable'.

Purchasers of the course are not buying a University of Melbourne 'experience', but a product; a discrete, stand-alone course. Consequently, there is no intention of providing students with access to more comprehensive university resources (e.g., access to the library), because they do not become members of the University.

The course is designed and delivered to have minimum impost on the University; an aim of the 'light touch' design. The main support that is offered to students is technical, through the Online Learning Support Team. The Welcome Handbook (half-a-page of A4) lists an email, telephone number, and job-log function. Depending on when a submission is made, a response may take up to 12 hours.

There is no academic support, although questions of an academic nature received by the Online Learning Support Team are channelled to the Course Director. The aforementioned Assessment Portal, which allows students to check on their progress, is an appropriate resource for a non-award bearing course. Similar information is available by requesting a course activity statement, which is sent to students by email.

The notion of web-accessibility has been given scant attention (see separate section below). If addressed, a statement about meeting the Web Content Accessibility Guidelines (WCAG) and advice on how students with disabilities can access special services would be an enhancement.

Suggestions for improving the existing course:

- Include statements about adherence to Web Content Accessibility Guidelines and how students with disabilities can access support to complete the course.

- Provide a glossary of terms used throughout the course.

\section{Instructional materials and design technologies}

Instructional materials and technologies refer to the design and use of documents, graphics, multimedia, and other technologies chosen by the course developers (Illinois Online Network, 1998-2019). Of the fourteen items rated in this category, 12 were rated as 'meets', one as developing, and one as 'not applicable'.

The course can be accessed on multiple devices. The tutorials have a consistent layout, using a simple font, with different font sizes for headings. The content and learning outcomes are situated in a light blue background; quizzes and 'stop and think' activities are in orange 'boxes', and buttons for 'tasks' are in a darker blue.

Each tutorial on the Knowledge Portal is contained on a single page, resulting in significant scrolling from top to bottom, with only one icon that allows you to return to the top of the page. Navigation aids are located in the same places in each tutorial, signposted with coloured fonts. The newer Student Learning Portal divides each tutorial into multiple pages, minimising the scrolling, and provides links to the different pages. The Student Learning Portal also houses the assessments, an improvement on separate Knowledge and Assessment Portals.

The video-files are generally of good quality with clear sound. The clips of university educators talking about clinical supervision are a strong feature. The videos from the Course Director are filmed 'on location' in Australia. They are less technically polished and have some background noise. The clip from the film 'The Poseidon Adventure' is also of a poorer quality. The videos are all relatively short and played comfortably on two devices.

The static images: photos, cartoons, and figures are clear. There are no unnecessary animations. Some of the 'stop and think' exercises are interactive, like 'drag and drop' activities, which are appropriate for the design. All the hyperlinks worked. 
- None. Scrolling has lessened on the newer Student Learning Portal and there is no longer a requirement to move to a different assessment platform.

\section{Accessibility}

The University of Melbourne aspires to comply with the Web Content Accessibility Guidelines (W3C Web Accessibility Initiative, 2005). The category of Accessibility addresses these guidelines, ensuring that course materials are accessible to everyone, with modifications being made to materials if necessary, in order to make them accessible to people with disabilities (Illinois Online Network, 1998-2019). Of the 16 items rated in this category, seven were rated 'meets', three 'developing', two 'non-existent', and four 'not applicable'.

Interviewed stakeholders suggested that compliance with the Web Content Accessibility Guidelines was unlikely to be a major consideration for the course's instructional designers (in some Learning Management Systems, for example CANVAS, the functionality can be pre-set for accessibility). Any adherence to the QOCl standards is therefore likely to be coincidental rather than intentional.

As neither of the report's authors identify as a person with disability, the comments that follow are cautiously made, and it is recommended that a more thorough accessibility evaluation is undertaken.

The tutorials are generally well-ordered and structured, and visual cues are used to group and separate content. 'Stop and think' exercises are signalled by coloured cells/boxes and signposting text. The good use of colours for contrast appears variable and may pose a challenge to accessibility for some students (i.e. those with colour-blindness). The course pages were still readable in high-contrast mode. Hyperlinks work well to take users to different parts of a tutorial.

Not all the graphics have associated captions, and none have captions embedded in them. The later would be considered to be good practice with respect to accessibility. The video-files are not closed captioned, although some do have a label and include the names of interviewees. Transcripts are not provided for video-content.

The principal 'moving content' is the video-content, which users can pause, stop, and restart. The spacebar and keyboard arrows can be used to stop and 'wind' the video-content, in addition to using the cursor. The up and down arrows can be used to scroll the pages. Students can use the tab function to move from one activity to the next in the Knowledge Portal but not in the post-tutorial assessments on the Assessment Portal.

The course brochure states that, "Program materials can be accessed through the eLearning Education app on Android or iOS, or on the web" (Mobile Learning Unit, n.d.-a), and on a webpage it is written that, "Our Mobile Learning Unit platform can be accessed, anytime, anywhere, on nearly any device!" (Mobile Learning Unit, n.d.-c). On a mobile device, some quizzes extended outside of the screen on portrait view.

Suggestions for improving the existing course:

- Review the entire course against the Web Content Accessibility Guidelines.

- Ask people with different impairments to review specific aspects of the course, e.g., navigability and use of colours.

- Embed captions in all graphics (e.g., cartoons and photographs).

- Provide closed captions on all videos.

- Provide access to text transcripts for video-content. 


\section{Course evaluation}

Course evaluation refers to the processes used to gather feedback from learners with the aim of improving the course (Illinois Online Network, 1998-2019). All three items in this category were rated 'developing'.

Students are required to complete an online course evaluation before the Certificate of Completion is released. The evaluation survey is generic, used across a number of courses offered by the Mobile Learning Unit. It is comprised of three sections related to course administration, delivery, and impact, with each section having a small number of Likert-items (14 in total) and an open text box.

The stem to the open text box on the Course Impact section has incorrect wording, repeating the wording from the earlier section, 'Do you have any additional comments regarding course administration?'. There is an irrelevant open text box in this section, with additional open question asking students to estimate how many hours they used 'the simulator'.

In the post tutorial assessments and the case studies there is a star-rating option with a text box (Box 3).

Box 3. Post-tutorial assessment and case study feedback form from the Student Learning Portal

\section{Feedback Form}

Would you like to leave this learning unit a rating and feedback?

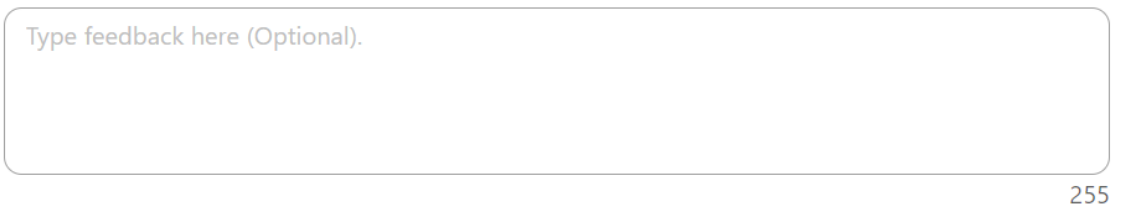

The final tutorial contains an open invitation from the Course Director to submit feedback to a generic e-mail address, but it has never been used. Determined students could provide feedback to the Online Learning Support Team via the inquiries e-mail, but this is not what it is intended for.

Although there are means for students to provide feedback, the tools and mechanisms are unlikely to provide rich information, and to date summary feedback reports from the Mobile Learning Unit to the Course Director have not been created.

\section{Suggestions for improving the existing course:}

- Minimally, correct the wording for the open text box in the Course Impact section of the survey and remove the question about the simulator.

- Review the feedback options with a view to generating more meaningful data to inform improvements in the CSO course. 


\section{Summary}

Evaluating the CSO course against the standards in the QOCI rubric provides both a benchmark and a means of identifying formative feedback that may help in improving the course as it is currently conceived as a 'light touch' program. The course was rated as meeting $70 \%$ of the items that we judged relevant for the 'light touch' design; meaning that it has many strengths. It is well-structured and logically sequenced; interactions with the content are well-supported by the technology; and the content itself is interactive, designed to support learning. The requisite low-impost on the University has been realised, whilst at the same time maintaining good technical support to students. The remaining 30\% of relevant rubric's items provide pointers for potential improvements to the course: such as, better compliance with Web Content Accessibility Guidelines; enhanced feedback to students on certain learning activities, improved and varied assessment of student achievement, and obtaining genuinely informative feedback from students about the course itself. The Discussion contains a broader debate, whether a modified course has any merit; one that aspires to meet the rubric's 33 items that we judged as not relevant for a 'light touch' design. 


\section{The implementation of the course}




\section{Overview}

Rudimentary learning analytics data were made available by the MLU, providing an insight into the duration of students' interactions with the course. As described in the Course evaluation section, students are also prompted to provide responses to a formal evaluation embedded within the CSO course. Students can complete this at the conclusion of the CSO course, which is a prerequisite to receiving a Certificate of Completion.

\section{Learning analytics}

Data with respect to the duration that students accessed particular sections of the course (e.g., tutorials, assessments) were analysed. The nature of the data collected highlighted a significant challenge with using this data to understand how students interacted with the sections of the CSO course. By way of example, Figure 4 provides a snapshot of the available data from a student who completed the entire CSO course.

Figure 4. Snapshot of the learning analytics data produced by the Customer Relationship Management (CRM) system.

\begin{tabular}{|c|c|c|c|c|c|c|}
\hline Tutorial 1: Study Guide & & 1.1 Study guide & Completed & 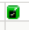 & 21/09/2020 12:31 PM & 21/09/2020 12:33 PM \\
\hline Subtotal & Count & 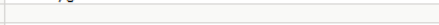 & 1 & 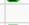 & - & 然 \\
\hline \multirow{6}{*}{ Tutorial 2: What is Clinical Supervision? } & & 2.1 introducton & completed & 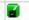 & 21/09/2020 12:33 PM & 22/09/2020 11:49 AM \\
\hline & & 2.2 Defining clinical supervision & Completed & . & 21/09/2020 12:33 PM & 22/09/2020 11:49 AM \\
\hline & & 2.3 Caring about learners & Completed & - & $21 / 09 / 202012: 33$ PM & $22 / 09 / 202011: 49$ AM \\
\hline & & 2.4 The excellent supervisor & Completed & 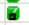 & 21/09/2020 12:33 PM & 22/09/2020 11:49 AM \\
\hline & & 2.5 Summary and references & Completed & 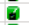 & 21/09/2020 12:33 PM & 22/09/2020 11:49 AM \\
\hline & & 2.7 End-of-Tutorial' Assessment Questions & Completed & 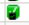 & 21/09/2020 12:33 PM & 22/09/2020 11:49 AM \\
\hline \multirow{7}{*}{ Tutorial 3: No-fuss Educational Theories } & Count & & & & & \\
\hline & & 3.1 Introduction & Completed & ¿ & $22 / 09 / 202011: 50 \mathrm{AM}$ & 27/09/2020 2:49 PM \\
\hline & & 3.2 Acquir ing expertise & Completed & - & 22/09/2020 11:50 AM & 27/09/2020 2:49 PM \\
\hline & & 3.3 Vygotsky & Completed & . & 22/09/2020 11:50 AM & 27/09/2020 2:49 PM \\
\hline & & 3.4 Consciaus incompetence & Completed & 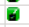 & $22 / 09 / 202011: 50 \mathrm{AM}$ & 27/09/2020 2:49 PM \\
\hline & & 3.5 Summaryand references & Completed & a & 22/09/2020 11:50 AM & 27/09/2020 2:49 PM \\
\hline & & 3.6 'End-of-Tutorial' Assessment Questions & Completed & . & 22/09/2020 11:50 AM & 27/09/2020 2:49 PM \\
\hline \multirow{7}{*}{ Tutorial 4: Coaching Clinical Learners } & Count & & & & & \\
\hline & & 4.1 introduction & Completed & ¿ & 22/09/2020 12:56 PM & 27/09/2020 2:49 PM \\
\hline & & 4.2 The nature of coaching & Completed & - & 22/09/2020 12:56 PM & 27/09/2020 2:49 PM \\
\hline & & 4.3 Balancing support and challenge & Completed & ๑ & 22/09/2020 12:56 PM & 27/09/2020 2:49 PM \\
\hline & & 4.4 Maintain ing motivation & Completed & 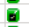 & 22/09/2020 12:56 PM & 27/09/2020 2:49 PM \\
\hline & & 4.6' End-of-Tutorial' Assessment Questions & Completed & 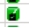 & 22/09/2020 12:56 PM & 27/09/2020 2:49 PM \\
\hline & & 4.5 References & Completed & . & 22/09/2020 12:56 PM & $27 / 09 / 20202: 49 \mathrm{PM}$ \\
\hline \multirow{8}{*}{ Tutorial 5: Feedback in Learner-Centred Clinical supervision } & Count & & 6 & & & \\
\hline & & 5.1 Introduction & Completed & a & 27/09/2020 10:35 AM & 27/09/2020 3:01 PM \\
\hline & & 5.2 Engaging the learner: connecting through feedback & Completed & घ & 27/09/2020 10:35 AM & 27/09/2020 3:01 PM \\
\hline & & 5.3 Setting and agreeing on goals & Completed & . & 27/09/2020 10:35 AM & 27/09/2020 3:01 PM \\
\hline & & 5.4 Effective feedback & Completed & 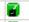 & 27/09/2020 10:35 AM & 27/09/2020 3:01 PM \\
\hline & & 5.5 AERO: A leamer-centred model for feedback & Completed & $\square$ & 27/09/2020 10:35 AM & 27/09/2020 3:01 PM \\
\hline & & 5.6 'End-of-Tutorial' Assessment Questions & Completed & a & 27/09/2020 10:35 AM & 27/09/2020 3:01 PM \\
\hline & & 5.5 Summ ary and references & Completed & a & 27/09/2020 10:35 AM & 27/09/2020 3:01 PM \\
\hline \multirow{6}{*}{ Tutorial 6: The Challenging Learner } & Count & & 7 & & & \\
\hline & & 6.1 introduction & Completed & ఉ & 27/09/20203:01 PM & 27/09/2020 3:51 PM \\
\hline & & 6.2 Causes of challenge & Completed & ๑ & 27/09/20203:01 PM & 27/09/2020 3:51 PM \\
\hline & & 6.3 A structured approach to difficult conversations: the ALECS model & Completed & ¿ & 27/09/20203:01 PM & 27/09/2020 3:51 PM \\
\hline & & 6.4 Summary and references & Completed & ¿ & 27/09/20203:01 PM & 27/09/2020 3:51 PM \\
\hline & & 6.5 'End-of-Tuorial' Assessment Questions & Completed & 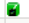 & 27/09/20203:01 PM & 27/09/2020 3:51 PM \\
\hline \multirow{8}{*}{ Tutorial 7: The Reflective Supervisor } & Count & & 5 & & & \\
\hline & & 7.1 Introduction & Completed & 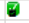 & 27/09/20203:51 PM & 27/09/2020 4:58 PM \\
\hline & & 7.2 Difficut supervisory contexts & Completed & a & 27/09/20203:51 PM & 27/09/2020 4:58 PM \\
\hline & & 7.3 The reflect ive supervisor & Completed & - & 27/09/20203:51 PM & 27/09/2020 4:58 PM \\
\hline & & 7.4 Seizing the moment & Completed & $\square$ & 27/09/20203:51 PM & 27/09/2020 4:58 PM \\
\hline & & 7.5 Farew ell & Completed & 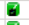 & 27/09/20203:51 PM & 27/09/2020 4:58 PM \\
\hline & & 7.6 References & Completed & 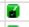 & 27/09/20203:51 PM & 27/09/2020 4:58 PM \\
\hline & & $7.7^{\prime}$ End-of Tucorial' Assessment Questions & Completed & ¿ & 27/09/20203:51 PM & 27/09/2020 4:58 PM \\
\hline \multirow{12}{*}{ Tutorial 8: Case Studies } & Count & & 7 & & & \\
\hline & & 8.7 Case Study 06 & Completed & $\approx$ & 27/09/20204:58 PM & 27/09/2020 6:02 PM \\
\hline & & 8.1 Introduction & Completed & 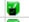 & 27/09/20204:58 PM & 27/09/2020 6:02 PM \\
\hline & & 8.2 Case Study 01 & Completed & 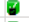 & 27/09/20204:58 PM & 27/09/2020 6:02 PM \\
\hline & & 8.3 Case Study 02 & Completed & - & 27/09/20204:58 PM & 27/09/2020 6:02 PM \\
\hline & & 8.4 Case Study 03 & Completed & ¿ & 27/09/20204:58 PM & 27/09/2020 6:02 PM \\
\hline & & 8.5 Case Study 04 & Completed & 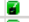 & 27/09/20204:58 PM & 27/09/2020 6:02 PM \\
\hline & & 8.6 Case Study 05 & Completed & \pm & 27/09/20204:58 PM & 27/09/2020 6:02 PM \\
\hline & & 8.8 Case Study 07 & Completed & 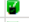 & 27/09/20204:58 PM & 27/09/2020 6:02 PM \\
\hline & & 8.9 Case Study 08 & Completed & - & 27/09/20204:58 PM & 27/09/2020 6:02 PM \\
\hline & & 8.10 Case Study 09 & Completed & ¿ & 27/09/20204:58 PM & 27/09/2020 6:02 PM \\
\hline & & 8.11 Case Study 10 & Completed & 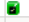 & 27/09/20204:58 PM & 27/09/2020 6:02 PM \\
\hline & Count & & 11 & & & \\
\hline \multirow{2}{*}{$\begin{array}{l}\text { Tutorial 9: Where to Nert } \\
\text { Subtotal }\end{array}$} & & 9.1 Introduction & Completed & $\square$ & 27/09/20206:02 PM & 27/09/2020 6:02 PM \\
\hline & $\begin{array}{l}\text { count } \\
\text { count }\end{array}$ & & $\begin{array}{c}1 \\
50\end{array}$ & & & \\
\hline
\end{tabular}

There are a number of challenges to the utilisation of the data, including its representativeness of how a student interacted with the module. For example, in Figure 4, the system indicated that nearly 24 hours was used to complete 'Tutorial 2: What is Clinical Supervision' or more than 5 days to complete 'Tutorial 3: No-fuss Educational Theories'. Another limitation with the available data is the lack of differentiation between the time taken to complete each individual section within a tutorial. As such, it is difficult to provide meaningful descriptive statistics summarising the learning analytics data - the data would lead to spurious interpretations.

Where more 'trustworthy' data were available, it suggested that students engaged with the content for each tutorial between three-quarters of an hour to one hour. This level of engagement appears to be consistent with the stated volume of up to 10 hours of 'screen time' for course completion. Figure 5 provides an example of student learning analytics data for this engagement duration. It is also worth noting that this student completed the course within one afternoon. However, this was not consistent across the participants - the majority of students who completed the 
course did so across multiple days (taking into account the aforementioned data issues). It is also not possible to draw from the learning analytics data any evidence supporting the assertion that learners wish to learn in short, five- to tenminute blocks of learning (Royse, n.d.-a).

Figure 5. Extract of learning analytics data for one student completing the Clinical Supervision Course over an afternoon.

\begin{tabular}{|c|c|c|c|}
\hline Com pleted & - & 24/09/2020 12:39 PM & 24/09/2020 3:41 PM \\
\hline Completed & : & 24/09/2020 3:41 PM & 24/09/2020 6:24 PM \\
\hline Com pleted & a & 24/09/2020 3:41 PM & 24/09/2020 6:24 PM \\
\hline Com pleted & - & 24/09/2020 3:41 PM & 24/09/2020 6:24 PM \\
\hline Com pleted & - & 24/09/2020 3:41 PM & 24/09/2020 6:24 PM \\
\hline Com pleted & (-) & 24/09/2020 3:41 PM & 24/09/2020 6:24 PM \\
\hline Com pleted & (]) & 24/09/2020 3:41 PM & 24/09/2020 6:24 PM \\
\hline \\
\hline Completed & ( & 24/09/2020 4:05 PM & 24/09/2020 6:24 PM \\
\hline Com pleted & - & 24/09/2020 4:05 PM & 24/09/2020 6:24 PM \\
\hline Com pleted & a & 24/09/2020 4:05 PM & 24/09/2020 6:24 PM \\
\hline Completed & a & 24/09/2020 4:05 PM & 24/09/2020 6:24 PM \\
\hline Com pleted & (a) & 24/09/2020 4:05 PM & 24/09/2020 6:24 PM \\
\hline Com pleted & - & 24/09/2020 4:05 PM & 24/09/2020 6:24 PM \\
\hline \\
\hline Com pleted & - & 24/09/2020 4:41 PM & 24/09/2020 5:01 PM \\
\hline Com pleted & a & 24/09/2020 4:41 PM & 24/09/2020 5:01 PM \\
\hline Com pleted & (a & 24/09/2020 4:41 PM & 24/09/2020 5:01 PM \\
\hline Com pleted & (a) & 24/09/2020 4:41 PM & 24/09/2020 5:01 PM \\
\hline Com pleted & a & 24/09/2020 4:41 PM & 24/09/2020 5:01 PM \\
\hline Com pleted & (a) & 24/09/2020 4:41 PM & 24/09/2020 5:01 PM \\
\hline \\
\hline Com pleted & (a) & 24/09/2020 5:01 PM & 24/09/2020 6:24 PM \\
\hline Com pleted & (a) & 24/09/2020 5:01 PM & 24/09/2020 6:24 PM \\
\hline Com pleted & - & 24/09/2020 5:01 PM & 24/09/2020 6:24 PM \\
\hline Completed & (a) & 24/09/2020 5:01 PM & 24/09/2020 6:24 PM \\
\hline Com pleted & (]) & 24/09/2020 5:01 PM & 24/09/2020 6:24 PM \\
\hline Com pleted & a & 24/09/2020 5:01 PM & 24/09/2020 6:24 PM \\
\hline Completed & - & 24/09/2020 5:01 PM & 24/09/2020 6:24 PM \\
\hline Com pleted & a & $24 / 09 / 2020$ 5:22 PM & 24/09/2020 6:25 PM \\
\hline Completed & (]) & 24/09/2020 5:22 PM & 24/09/2020 6:25 PM \\
\hline Com pleted & a & 24/09/2020 5:22 PM & 24/09/2020 6:25 PM \\
\hline Completed & - & 24/09/2020 5:22 PM & 24/09/2020 6:25 PM \\
\hline Completed & - & 24/09/2020 5:22 PM & 24/09/2020 6:25 PM \\
\hline & & \\
\hline Com pleted & a & 24/09/2020 5:30 PM & 24/09/2020 6:25 PM \\
\hline Completed & - & 24/09/2020 5:30 PM & 24/09/2020 6:25 PM \\
\hline Com pleted & a & 24/09/2020 5:30 PM & 24/09/2020 6:25 PM \\
\hline Completed & - & $24 / 09 / 20205: 30 \mathrm{PM}$ & 24/09/2020 6:25 PM \\
\hline Com pleted & - & 24/09/2020 5:30 PM & 24/09/2020 6:25 PM \\
\hline Com pleted & (]) & 24/09/2020 5:30 PM & 24/09/2020 6:25 PM \\
\hline Completed & - & 24/09/2020 5:30 PM & 24/09/2020 6:25 PM \\
\hline Completed & a & 24/09/2020 5:50 PM & 24/09/2020 6:24 PM \\
\hline Com pleted & - & 24/09/2020 5:50 PM & 24/09/2020 6:24 PM \\
\hline Completed & (a) & 24/09/2020 5:50 PM & 24/09/2020 6:24 PM \\
\hline Com pleted & - & 24/09/2020 5:50 PM & 24/09/2020 6:24 PM \\
\hline Com pleted & - & 24/09/2020 5:50 PM & 24/09/2020 6:24 PM \\
\hline Com pleted & a & 24/09/2020 5:50 PM & 24/09/2020 6:24 PM \\
\hline Completed & (] & 24/09/2020 5:50 PM & 24/09/2020 6:24 PM \\
\hline Com pleted & 밈 & 24/09/2020 5:50 PM & 24/09/2020 6:24 PM \\
\hline Completed & a & 24/09/2020 5:50 PM & 24/09/2020 6:24 PM \\
\hline Completed & - & 24/09/2020 5:50 PM & 24/09/2020 6:24 PM \\
\hline Com pleted & - & 24/09/2020 5:50 PM & 24/09/2020 6:24 PM \\
\hline Completed & (a) & $24 / 09 / 20206: 20 \mathrm{PM}$ & 24/09/2020 6:20 PM \\
\hline
\end{tabular}

A minority of students appeared to expedite their progress through the CSO course. For example, the data for one such student is presented in Figure 6. This student nominally completed the entirety of the CSO course in 19 minutes. Where students did not complete the entire CSO course, the number of tutorials that the students interacted with varied from one to eight, and a variable level of interaction was also observed for the components of individual tutorials. 
Figure 6. Learning analytics data from one student who completed the course in a short time period.

\begin{tabular}{|c|c|c|c|}
\hline Completed & - & 28/09/2020 8:25 PM & 28/09/2020 8:26 PN \\
\hline Completed & - & 28/09/2020 8:26 PM & 28/09/2020 8:38 PN \\
\hline Completed & ] & 28/09/2020 8:26 PM & $28 / 09 / 20208: 38 \mathrm{PN}$ \\
\hline Completed & 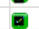 & 28/09/2020 8:26 PM & 28/09/2020 8:38 PN \\
\hline Completed & 司 & 28/09/2020 8:26 PM & 28/09/2020 8:38 PN \\
\hline Completed & - & 28/09/2020 8:26 PM & 28/09/2020 8:38 PN \\
\hline Completed & - & 28/09/2020 8:26 PM & 28/09/2020 8:38 PN \\
\hline Completed & 0 & 28/09/2020 8:38 PM & $28 / 09 / 20208: 39 \mathrm{PN}$ \\
\hline Completed & . & 28/09/2020 8:38 PM & 28/09/2020 8:39 PN \\
\hline Completed & - & 28/09/2020 8:38 PM & 28/09/2020 8:39 PN \\
\hline Completed & 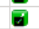 & 28/09/2020 8:38 PM & 28/09/2020 8:39 PN \\
\hline Completed & - & 28/09/2020 8:38 PM & 28/09/2020 8:39 PN \\
\hline Completed & - & 28/09/2020 8:38 PM & 28/09/2020 8:39 PN \\
\hline Completed & - & 28/09/2020 8:39 PM & 28/09/2020 8:40 PN \\
\hline Completed & . & 28/09/2020 8:39 PM & $28 / 09 / 20208: 40 \mathrm{PN}$ \\
\hline Completed & $\square$ & 28/09/2020 8:39 PM & 28/09/2020 8:40 PN \\
\hline Completed & 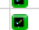 & 28/09/2020 8:39 PM & $28 / 09 / 20208: 40 \mathrm{PN}$ \\
\hline Completed & - & 28/09/2020 8:39 PM & $28 / 09 / 20208: 40 \mathrm{PN}$ \\
\hline Completed & E & $28 / 09 / 2020$ 8:40 PM & $28 / 09 / 20208: 41 \mathrm{PN}$ \\
\hline Completed & 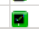 & $28 / 09 / 20208: 40$ PM & $28 / 09 / 20208: 41 \mathrm{PN}$ \\
\hline Completed & - & $28 / 09 / 20208: 40 \mathrm{PM}$ & 28/09/2020 8:41 PN \\
\hline Completed & - & 28/09/2020 8:40 PM & 28/09/2020 8:41 PN \\
\hline Completed & $\overline{0}$ & 28/09/2020 8:40 PM & 28/09/2020 8:41 PN \\
\hline Completed & 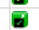 & $28 / 09 / 20208: 40 \mathrm{PM}$ & 28/09/2020 8:41 PN \\
\hline Completed & 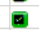 & 28/09/2020 8:40 PM & 28/09/2020 8:41 PN \\
\hline Completed & च & 28/09/2020 8:41 PM & 28/09/2020 8:42 PN \\
\hline Completed & 司 & 28/09/2020 8:41 PM & 28/09/2020 8:42 PN \\
\hline Completed & $\overline{0}$ & 28/09/2020 8:41 PM & $28 / 09 / 20208: 42 \mathrm{PN}$ \\
\hline Completed & a & 28/09/2020 8:41 PM & $28 / 09 / 20208: 42 \mathrm{PN}$ \\
\hline Completed & 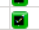 & 28/09/2020 8:41 PM & 28/09/2020 8:42 PN \\
\hline Completed & - & 28/09/2020 8:42 PM & 28/09/2020 8:43 PN \\
\hline Completed & - & 28/09/2020 8:42 PM & 28/09/2020 8:43 PN \\
\hline Completed & 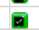 & 28/09/2020 8:42 PM & 28/09/2020 8:43 PN \\
\hline Completed & - & 28/09/2020 8:42 PM & $28 / 09 / 20208: 43 \mathrm{PN}$ \\
\hline Completed & - & 28/09/2020 8:42 PM & 28/09/2020 8:43 PN \\
\hline Completed & - & 28/09/2020 8:42 PM & 28/09/2020 8:43 PN \\
\hline Completed & $\bar{\Xi}$ & 28/09/2020 8:42 PM & 28/09/2020 8:43 PN \\
\hline Completed & D & 28/09/2020 8:43 PM & 28/09/2020 8:44 PN \\
\hline Completed & - & 28/09/2020 8:43 PM & 28/09/2020 8:44 PN \\
\hline Com pleted & - & 28/09/2020 8:43 PM & $28 / 09 / 20208: 44 \mathrm{PN}$ \\
\hline Completed & $\overline{0}$ & 28/09/2020 8:43 PM & 28/09/2020 8:44 PN \\
\hline Completed & a & 28/09/2020 8:43 PM & 28/09/2020 8:44 PN \\
\hline Completed & - & 28/09/2020 8:43 PM & $28 / 09 / 20208: 44 \mathrm{PN}$ \\
\hline Completed & - & 28/09/2020 8:43 PM & 28/09/2020 8:44 PN \\
\hline Completed & $\overline{0}$ & 28/09/2020 8:43 PM & 28/09/2020 8:44 PN \\
\hline Completed & $\overline{0}$ & 28/09/2020 8:43 PM & 28/09/2020 8:44 PN \\
\hline Completed & a & 28/09/2020 8:43 PM & 28/09/2020 8:44 PN \\
\hline Completed & - & 28/09/2020 8:43 PM & $28 / 09 / 20208: 44 \mathrm{PN}$ \\
\hline Completed & - & 28/09/2020 8:44 PM & 28/09/2020 8:44 PN \\
\hline
\end{tabular}

\section{Course administration - formal course evaluation data}

Students who wished a Certification of Completion had to complete an evaluation of their experience of engaging with the CSO course. Data used to inform this section of the analysis was based on 119 responses during the period June 1 2019 to October 7 2020. Respondents were likely to agree or strongly agree with the statements about access to the CSO course and supports. Given the 'light touch' approach to design, it is anticipated that interaction with a member of the MLU or an academic would be less likely for the CSO course (Table 6).

Nearly three-quarters of respondents ( $n=8773.1 \%$ ) agreed or strongly agreed with the support services being "easy to access" with 39 respondents (32.8\%) not accessing any supports. However, it was not clear how 'support services' was defined (e.g., access to the online help function, access to MLU team members) and the 'not applicable' option responses were variable. Where respondents stated that they had accessed assistance from either the (Online Learning) support team or an academic contact for the CSO course, they were likely to again agree or strongly agree with the promptness of responses (support team $-n=108,90.8 \%$; academic team $-n=61,51.3 \%)^{15}$.

\footnotetext{
${ }^{15} \mathrm{n}=58$ (48.7\%) indicated that they did not access support from academic support team. None of the students were put in touch with the Course Director. Responses to this item on the evaluation may have been due to the wording of the items - further evidence of the limitation of the current post-course evaluation tool.
} 
Table 6. Post-course evaluation responses related to the administration of the Clinical Supervision Online course ( $n=119)$.

\begin{tabular}{|l|c|c|c|c|c|}
\hline \multicolumn{1}{|c|}{ Item } & Strongly agree & Agree & Disagree & Strongly disagree & Not applicable \\
\hline $\begin{array}{l}\text { Instruction } \\
\text { emails were } \\
\text { useful and clear }\end{array}$ & $42(35.3 \%)$ & $67(56.3 \%)$ & $5(4.2 \%)$ & $3(2.5 \%)$ & $2(1.7 \%)$ \\
\hline $\begin{array}{l}\text { Support services } \\
\text { were easy to } \\
\text { access }\end{array}$ & $28(23.5 \%)$ & $48(40.3 \%)$ & $3(2.5 \%)$ & $1(0.8 \%)$ & $39(32.8 \%)$ \\
\hline $\begin{array}{l}\text { The support } \\
\text { team were } \\
\text { knowledgeable } \\
\text { with their } \\
\text { responses }\end{array}$ & $27(22.7 \%)$ & $39(32.8 \%)$ & $3(2.5 \%)$ & 0 & $50(42.0 \%)$ \\
\hline $\begin{array}{l}\text { The support } \\
\text { team were } \\
\text { prompt with } \\
\text { their responses }\end{array}$ & $28(23.5 \%)$ & $41(34.5 \%)$ & $1(0.8)$ & 0 & $49(41.2 \%)$ \\
\hline $\begin{array}{l}\text { The academic } \\
\text { team were } \\
\text { prompt with } \\
\text { their responses }\end{array}$ & $23(19.3 \%)$ & $38(31.9 \%)$ & 0 & 0 & $58(48.7 \%)$ \\
\hline
\end{tabular}

Open-ended survey questions rarely generate rich qualitative data (LaDonna et al., 2018). Given this reality, coupled with the small number of written responses, we opted not to undertake a rigorous qualitative analysis of the written comments ${ }^{16}$. A rudimentary content analysis of open text responses with respect to the course administration suggested that respondents' experiences were positive:

"But the support staff were definitely helpful."

"I was taken to the 1st assessment task without doing the tutorial. The mobile learning phone line were helpful and did get me set up. But it took a long time and was very frustrating."

A small number of respondents did identify an issue with course access and the platform:

"Having some direction to access the modules from Canvas would have been helpful."

"It might have been worthwhile notifying us that there were two different platforms for the course and the assessment to minimise confusion."

As previously highlighted, the MLU moved the mobile learning platform from separate components into a single, streamlined program (incorporating content and assessment). This change may have resulted in improvements in the student experience.

\footnotetext{
${ }^{16}$ Due to the nature of the 'thin' qualitative data from the open text boxes, the quotations that are provided in the report are not offered as evidence of strong themes, but as reflecting the range of individualistic responses to the course evaluation.
} 


\section{Course delivery - formal course evaluation data}

The evaluation of the delivery of the CSO course focused on the mobile learning platform. Data used to inform this section of the analysis was based on 118 responses during the period June 12019 to October $72020 .{ }^{17}$ Evaluation data suggested that the respondents accessed the CSO course through the 'webviewer' with nearly all respondents agreeing or strongly agreeing $(n=114,95.8 \%)$ that this was an easy method by which the content could be accessed (Table 7). A smaller number of respondents accessed the CSO course through the MLU mobile learning application. Again, the majority of respondents agreed or strongly agreed with statements regarding ease of installation ( $n=72$, $60.9 \%$ ) and ease of use of the mobile learning application ( $n=71,59.7 \%)$. Over a third of respondents indicated 'not applicable' to these two items, suggesting they did not use the mobile learning application, preferring the 'webviewer'.

Table 7. Post-course evaluation responses related to the delivery of the Clinical Supervision Online course ( $n=118)$.

\begin{tabular}{|l|c|c|c|c|c|}
\hline \multicolumn{1}{|c|}{ Item } & Strongly agree & Agree & Disagree & Strongly disagree & Not applicable \\
\hline $\begin{array}{l}\text { It was easy to } \\
\text { access course } \\
\text { materials online } \\
\text { with the } \\
\text { webviewer }\end{array}$ & $63(52.9 \%)$ & $51(42.9 \%)$ & $2(1.7 \%)$ & $1(0.8 \%)$ & $1(0.8 \%)$ \\
\hline $\begin{array}{l}\text { It was easy to } \\
\text { install the app on } \\
\text { my device }\end{array}$ & $39(32.8 \%)$ & $33(27.7 \%)$ & $2(1.7 \%)$ & $2(1.7 \%)$ & $42(35.3 \%)$ \\
\hline $\begin{array}{l}\text { The app was easy } \\
\text { to use }\end{array}$ & $41(34.5 \%)$ & $30(25.2 \%)$ & $4(3.4 \%)$ & 0 & $43(36.1 \%)$ \\
\hline $\begin{array}{l}\text { The assessment } \\
\text { portal was user- } \\
\text { friendly }\end{array}$ & $54(45.4 \%)$ & $52(43.7 \%)$ & $8(6.7 \%)$ & $1(0.8 \%)$ & $(2.5 \%)$ \\
\hline $\begin{array}{l}\text { The course } \\
\text { content was } \\
\text { interactive }\end{array}$ & $61(51.3 \%)$ & $54(45.4 \%)$ & $2(1.7 \%)$ & $1(0.8 \%)$ & 0 \\
\hline
\end{tabular}

Interactivity of the course content was rated highly by the respondents, with all but four agreeing or strongly agreeing. The videos as part of each module were perceived to be very helpful:

"[The Course Director's] videos were wonderful - short and concise that tied the content of each module together clearly."

${ }^{17}$ One student did not complete this section of the evaluation. 
However, a small number of respondents suggested the volume of interactive videos could be reduced or identified issues with access:

"The videos featuring other clinical supervisors relating their experiences got a bit draggy. It doesn't become relevant after the first couple of videos, because they start talking about personal experiences and feelings, which as a student sitting behind a computer I cannot really relate to."

"I found it hard to play the video and input answers during the tutorials on the phone."

"I did find some of the videos would not play fluently."

The majority of respondents agreed with the statement about the user-friendliness of the assessment portal ( $n=106$, 89.1\%). Whilst the majority of respondents had a positive experience, a number identified issues moving between the content and assessment sections; an issue that has been resolved by moving the CSO course to the integrated Student Learning Portal:

"A bit clumsy moving between two separate pages for the assessment and tutorial."

"I did find it a bit clunky: having to go from the assessments back to the tutorials."

Overall, respondents were largely positive about the course, as typified by the following:

"I liked the varied information/videos/ and real life teachers commentary."

"I found the use of case studies, quizzes and videos very useful. I learn best by considering clinical scenarios so this was much appreciated."

\section{Case reports}

The Mobile Learning Unit (MLU) manages all communications from students, most of which are via e-mail and are known as 'case reports'. Table 8 summarises the 79 case reports received by the Online Learning Support Team over a period of about 16 months into six categories. The number of inquiries serves as a proxy indicator for how well the course in being implemented. Using the figure of 204 enrolments, about one in three students submits an inquiry, with 'accessing course material' accounting for $41 \%$ of the inquiries.

Table 8. 'Case reports' logged with the Online Learning Support Team by categorya

\begin{tabular}{|l|c|}
\hline Case reason & Frequency \\
\hline Business development - inquiries about group purchases & 5 \\
\hline Course material access & 32 \\
\hline Password problem & 5 \\
\hline $\begin{array}{l}\text { General inquiry - seeking course information, purchase issues, and not receiving any email } \\
\text { after purchasing }\end{array}$ & 24 \\
\hline IT issue inquiry & 12 \\
\hline UoM Cert inquiry & 1 \\
\hline Total & $\mathbf{7 9}$ \\
\hline
\end{tabular}

a The report we received was dated as searching between January $1^{\text {st }} 2019$ and October $20^{\text {th }} 2020$. As the first enrolment was in June 2019, the 79 inquiries were more likely to be received over 16 months.

The small number inquiries, little more than an inquiry a week, reflects the course's 'light touch' design; the intention that the course should require little day-to-day input from the University's academic or professional staff. This finding 
is also consistent with the course's formal evaluation data, where nearly half of the respondents identified not accessing any supports. The course appears to be effectively meeting this 'light touch' aim. As none of the inquiries to date have been of an academic nature, the course has successfully protected educator time.

\section{Collecting and using student 'demographic' data}

A significant weakness in the Mobile Learning Unit's monitoring and reporting functions relates to the use of the CRM system to collect, collate, and analyse demographic data about the course's students. As well as supplying contact details, an online registration form asks that students supply some cursory information about themselves and how they heard about the course; essential information from both educational and marketing perspectives (Box 4). We were advised that this information could not be automatically summarised in a report and we elected not to ask for and manually collate the data from hard-copies of 204 individual registration forms. A separate report, listing Title, Specialty, and Hospital/Organisation against students' enrolment numbers was almost entirely void of data.

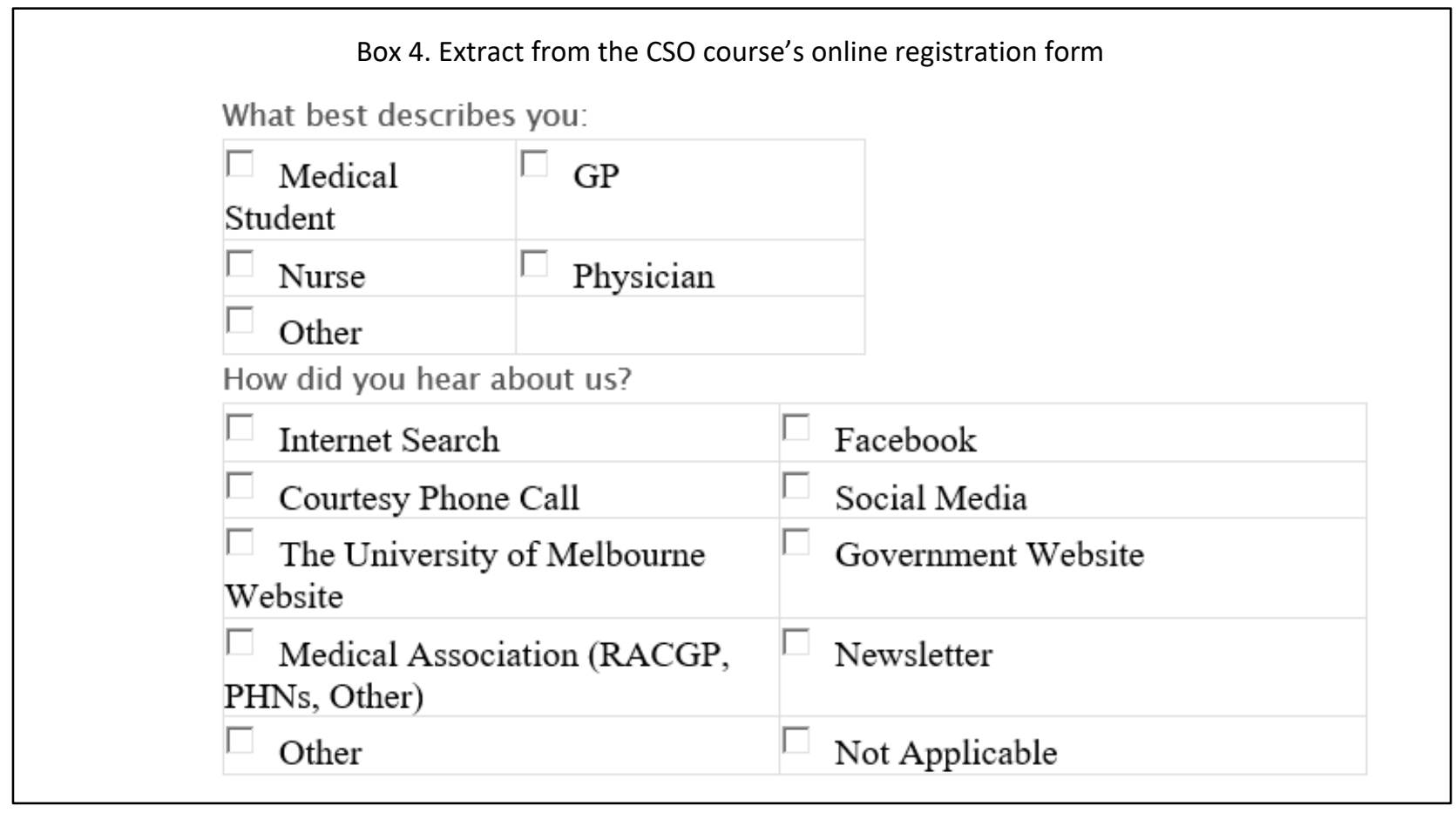

As well as the information currently requested, there are additional questions that would be helpful to ask to gain greater understanding about who is enrolling for the course. For example, whether students are existing clinical supervisors, and if so, how long have they been supervising.

Suggestions for improving the existing course:

- Review the available learning analytics data and establish whether it is possible to refine how this data is collected (particularly engagement duration) to improve accuracy.

- Review the processes for capturing and reporting on student 'demographic' data.

- Review the data currently being collected, with the aim of enhancing the information to support both educational and marketing functions. Marketing-specific input would be of assistance in this review. 


\section{Course impact - formal course evaluation data}

As highlighted in the Methods section of this report, evaluation of impact is challenging and not possible for the reasons previously described. However, using the data available from the MLU it is possible to begin to build a picture of the students' experience of the CSO course.

Data used to inform this section of the analysis was based on 118 responses during the period June 12019 to October 72020 . Students' expectations of the course were met for the vast majority of course evaluation respondents, with 97.5\% ( $n=116)$ indicating they agreed or strongly agreed with this statement (Table 9). A similar outcome was observed with respect to the appropriateness of the course for the students' current role with $97.6 \%$ ( $n=115)$ agreeing or strongly agreeing. Students were also invited to respond to the statement, "I have applied what I have learned to my day-to-day practice". Again, the majority of respondents agreed ( $n=60,50.4 \%)$ or strongly agreed $(n=53,44.5 \%)$ with the statement. Only two respondents (1.7\%) would not recommend the CSO course to their peers.

Table 9. Post-course evaluation responses related to the outcomes of the Clinical Supervision Online course (n=119).

\begin{tabular}{|l|c|c|c|c|c|}
\hline \multicolumn{1}{|c|}{ Item } & Strongly agree & Agree & Disagree & Strongly disagree & Not applicable \\
\hline $\begin{array}{l}\text { The course } \\
\text { delivered was } \\
\text { what I expected }\end{array}$ & $50(42.0 \%)$ & $66(55.5 \%)$ & $2(1.7 \%)$ & $1(0.8 \%)$ \\
\hline $\begin{array}{l}\text { The course was } \\
\text { appropriate for } \\
\text { me in my current } \\
\text { role }\end{array}$ & $64(53.8 \%)$ & $52(43.7 \%)$ & $2(1.7 \%)$ & 0 & $1(0.8 \%)$ \\
\hline $\begin{array}{l}\text { I have applied } \\
\text { what I have } \\
\text { learned to my } \\
\text { day-to-day } \\
\text { practice }\end{array}$ & $53(44.5 \%)$ & $60(50.4 \%)$ & $3(2.5 \%)$ & 0 & $3(2.5 \%)$ \\
\hline $\begin{array}{l}\text { I would } \\
\text { recommend the } \\
\text { course to my } \\
\text { peers }\end{array}$ & $62(52.1 \%)$ & $54(45.4 \%)$ & $2(1.7 \%)$ & 0 & $1(0.8 \%)$ \\
\hline
\end{tabular}

From an analysis of the open-text responses, respondents suggested that the level at which the CSO course was pitched was appropriate for them:

"Excellent course covering principles of good clinical supervision."

"Course was excellent - I am a nurse and have been in an informal teaching role so have not required this background previously."

"I think the course would still be appreciated and relevant to the more experienced supervisor. It was pitched in such a positive way, so I think it would help experienced supervisors who have bad habits reflect and consider alternative methods."

"The case studies were a very effective and engaging way of consolidating the learning material."

"The short course indeed very valuable and an eye-opener for a novice supervisor like me. I would recommend this to all the junior supervisors." 
Respondents also provided open-text comments on how to improve or extend the engagement with the CSO course content, moving it beyond the 'light touch' design:

"I think the modules could promote deeper learning and application if they were linked to discussion boards, or included webinars, or more specific self-directed assignments. I know that is not the purpose of the course, but it could be readily extended to offer deeper application."

"Important part of supervision training is the discussions, the comments, meeting others and hearing their experiences or them reflecting on yours. Online if face-to-face not available."

\section{Post-tutorial assessments and case studies star-ratings textbox}

Each post-tutorial assessment and end-of-course case study provides students with the opportunity to allocate a starrating and provide written feedback (Boxes 3 and 5). Box 5, with the stem, 'Would you like to leave this learning unit a rating and feedback?' is from the newer Student Learning Portal and Box 3, with no corresponding guidance, is from the original Assessment Portal.

Box 5. Post-tutorial assessment and case study feedback form from the Assessment Portal

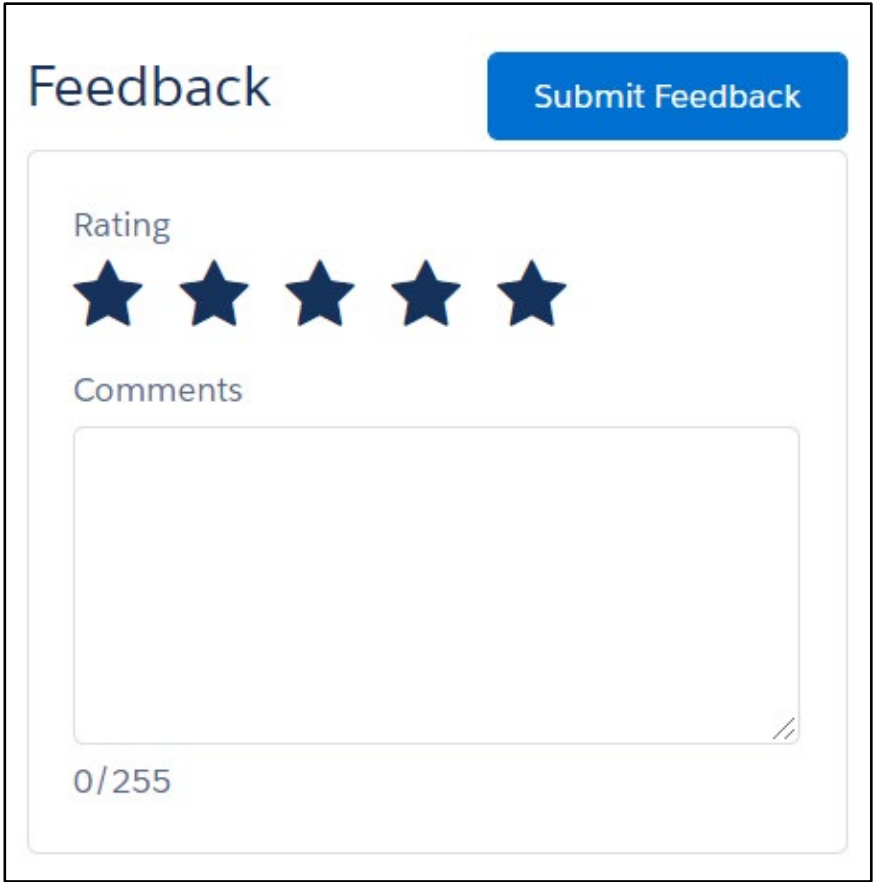

This feedback method offers every student a further sixteen opportunities to provide feedback about the course. The difference between the two invitations is noteworthy, because in relation to the six tutorials, they guide respondents to focus on different aspects of the course. The stem from the Student Learning Portal invites any comment about the preceding tutorial, but because the original course uses a separate Assessment Portal, and provides no guidance, it seems to be asking for feedback about the post-tutorial assessments only ${ }^{18}$. This may seem a minor point, but it should be considered in a broader debate about the purpose and effectiveness of the course's formal feedback

\footnotetext{
${ }^{18}$ At the risk of being pedantic, we suggest congruence in the language used. The stem might read, 'Would you like to leave this tutorial a rating and feedback?' rather than 'learning unit'.
} 
processes. It is in this spirit that we offer some data and commentary about the feedback rating process from the Knowledge and Assessment Portals, highlighting in advance that the data reveals little of any value.

Figures 7 and 8 show the number of star ratings and written comments provided by students on the Knowledge and Assessment Portals respectively. An 'eyeball analysis' suggests a decline in feedback overtime on the Knowledge Portal, with written comments being less frequent; whereas the feedback on the Assessment Portal is more constant over time, with written comments similarly being less frequent. There are various reasons why people do not respond to surveys, with 'evaluation fatigue', a consequence of over-surveying people, and disappearing feedback, that is, never receiving any feedback findings being two major causes (Goyder, 2008).

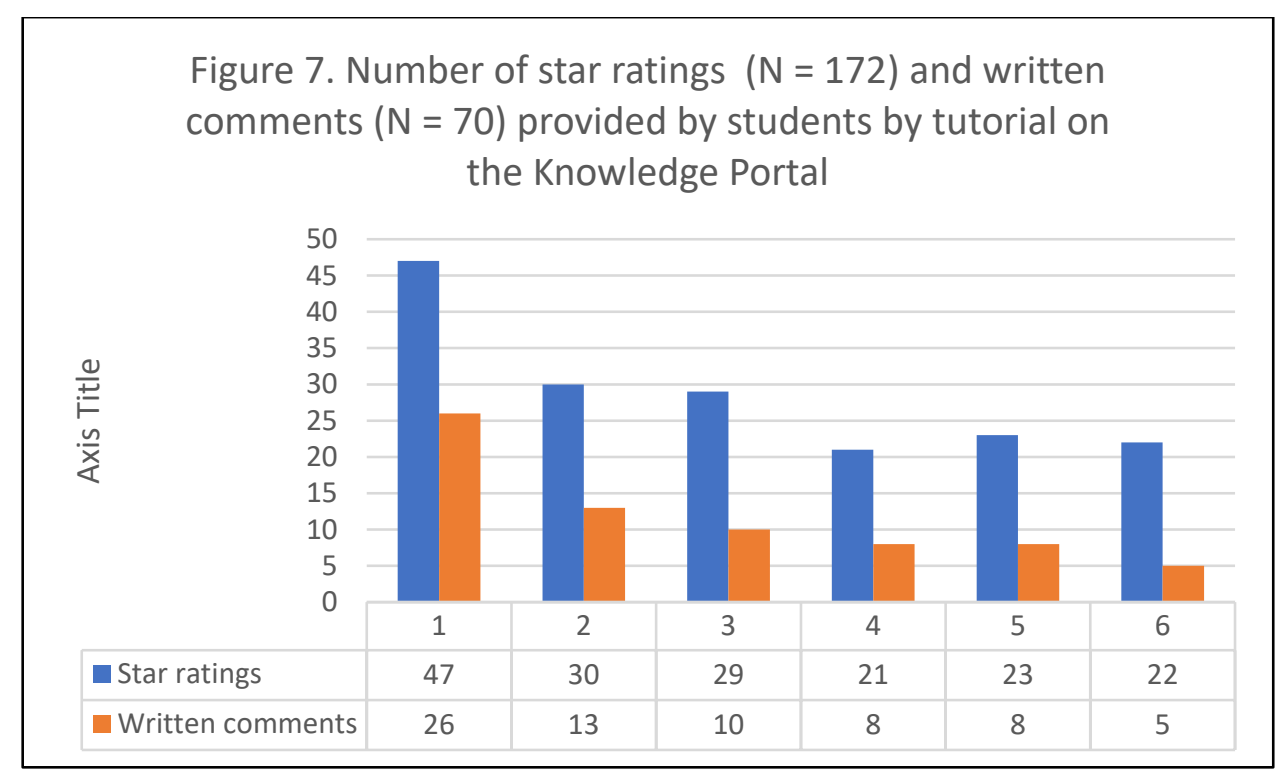

On the Knowledge Portal, star ratings were given in $27 \%$ of all possible instances and comments were given in $11 \%$ of all possible occasions. On the Assessment Portal, star ratings were given in $18 \%$ of all possible instances and comments were given in $4 \%$ of all possible occasions ${ }^{19}$. The mean star rating was 4.6 stars and 4.5 stars respectively.

The value of the ratings and the comments is reduced by high non-response rates, with issues of error and bias likely to be a factor in any interpretation of the selective feedback. (As the next Section shows, a significant portion of students elected not to complete the post-tutorial assessments or the end-of-course case studies, precluding any ratings/comments.)

\footnotetext{
${ }^{19}$ These figures were calculated from a report generated on 9 November 2020, stating 167 enrolments. After allowing for students who had not completed post-tutorial assessments or end-of-course case studies, there were 642 possible star ratings/comments on the Knowledge Portal and 928 on the Assessment Portal.
} 


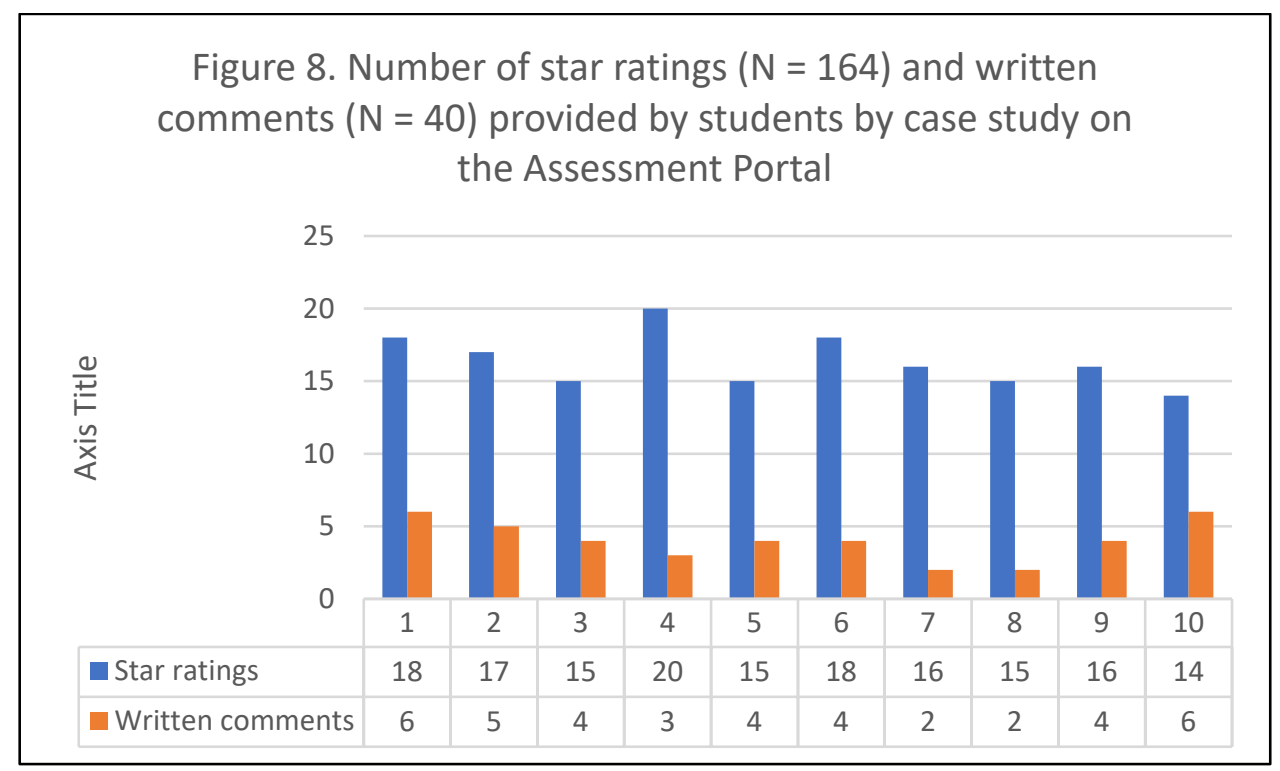

A cursory analysis of the small number of written comments were grouped into two broad categories - affirming and challenging - that may be useful to the course designers in respectively supporting the current educational design or prompting a re-think, as the following quotations illustrate.

\section{Affirming comments ${ }^{20}$}

"That was the most useful but brief summary I have read on key educational theories." (Comment on Tutorial 2)

"Good case highlighting boundary and responsibility of a supervisor towards a learner, as well as issues surrounding confidentiality and support for learner in difficulties." (Comment on case study 6)

\section{Challenging comments}

"Level of information is beginner level. I don't feel I have learnt new information from Tutorial 1 to apply to my supervisor role. Good basic principles reinforced." (Comment on Tutorial 1)

"Again, I feel there are a number of ways this could be handled - your multiple-choice answers were one way - whether that is "correct" or not? Even gently confronting at the time may not go well." (Comment on case study 9$)^{21}$

\section{Utility of formal course evaluation data}

The two formal course evaluation processes, the end-of-course evaluation and the embedded star ratings/comments, assess 'reaction', the first level in Kirkpatrick's four-level training evaluation model. This level considers the degree to which students found the course favourable, engaging, and relevant to their work (Yardley \& Dornan, 2012). Collecting data in this way is practical and costs little to collect, but the course team should deliberate whether this evaluation

\footnotetext{
${ }^{20}$ It may be tempting to use affirming comments such as these in marketing campaigns. This probably falls into Patton's (2008) category regarding the misuse of evaluation data; that is, selectively using data to support a particular purpose.

${ }^{21}$ On page 19 we noted that answers to the MCQs were more nuanced than an absolute 'right' or 'wrong' and were therefore likely to be disputed by students. This student's response is one of several examples of students wanting to debate the given 'correct' response.
} 
data is useful both for marketing and course development/improvement. As previously mentioned, no summary feedback reports have yet been created, which is minimally discourteous to the respondents and unhelpful if the intention behind collecting the data is formative. At present, the course's formal evaluation approaches have the appearance of what Patton (2008) labels a 'quick and dirty evaluation', a low-budget effort, which gives the appearance of evaluation, but offers little value and short-lived utility.

Suggestions for improving the existing course:

- Review the course evaluation processes, with a view to generating more meaningful information (beyond student 'reaction').

- Set dates to generate and review formal course evaluation data. Depending upon student numbers this could be every 12- or 24-month period.

\section{Course completion rates}

The estimated amount of 'screen time' to complete the course of between six to ten hours is not onerous, but as Table 10 shows, 56 (39\%) of the 142 students who had enrolled up until the end of June 2020 were judged not to have completed the course. As the students paid their course fees up-front there is no immediate financial cost to the University, but there may be longer-term costs to the institution. For example, neutral or negative word-of-mouth reviews from these students about the course may close-off potential enrolments or result in reputational harm. From the students' perspective, spending money on a course one does not complete may result in adverse financial and emotional implications (van Ameijde et al., 2018). Not completing the course is also likely to have a bearing on students' knowledge and understanding of the clinical supervisor's role and effectively applying that knowledge in the workplace (i.e., course impact).

Table 10. Number of students that did not complete the Clinical Supervision Online course by month from June 2019 to June 2020.

\begin{tabular}{|c|c|c|c|c|c|c|c|c|c|c|c|c|c|c|c|c|}
\hline Month & $\begin{array}{l}\stackrel{0}{\circ} \\
\stackrel{1}{1} \\
\stackrel{5}{3}\end{array}$ & $\overrightarrow{\bar{z}}$ & $\stackrel{00}{\frac{00}{4}}$ & $\stackrel{+}{0}$ & 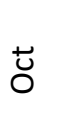 & ò & ڤั & 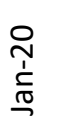 & ब्थ & $\sum^{\frac{1}{\pi}}$ & 高 & $\sum^{\vec{\pi}}$ & 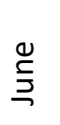 & $\overline{\grave{z}}$ & $\stackrel{00}{\frac{10}{2}}$ & $\stackrel{+}{0}$ \\
\hline $\begin{array}{l}\text { Enrolments } \\
\text { per month }\end{array}$ & 20 & 5 & 45 & 14 & 2 & 1 & 1 & 4 & 3 & 3 & 5 & 12 & 27 & 9 & 48 & 5 \\
\hline $\begin{array}{l}\text { Students } \\
\text { listed as } \\
\text { not } \\
\text { completing } \\
\text { the course }^{b}\end{array}$ & 3 & 2 & 12 & 6 & 1 & 1 & 0 & 3 & 2 & 1 & 2 & 4 & 19 & & & \\
\hline
\end{tabular}

${ }^{a}$ First enrolment 14/06/19

${ }^{b}$ Non-completion defined as not completing the course within three calendar months. [Report was generated on 08/10/20. Only includes students enrolled on the original Knowledge and Assessment Portals.]

There is a body of research that has examined why students drop-out of online programs; often used as a measure of effectiveness. Although failure to complete a short course is the context here, it seems reasonable to relate the 
findings of this research to the course's high non-completion rate. Willging and Johnson (2009) conclude that the reasons for dropping out of a distance education course are complex, multiple, and inter-related but they typically reflect poorly on a course, often implying ineffectiveness or poor quality.

For the 56 students identified as not completing the course, Tables 11 and 12 show how many of the post-tutorial assessments and end-of-course case studies they completed. $61 \%$ of students who did not complete the course did not complete a single post-tutorial assessment.

Table 11. Completion of post-tutorial assessments by students who did not complete the course from June 2019 to June 2020 ( $\mathrm{N}=56$ ).

\begin{tabular}{|l|l|l|l|l|l|l|l|}
\hline Number of post-tutorial assessments completed & 0 & 1 & 2 & 3 & 4 & 5 & 6 \\
\hline Number of students ( $\mathbf{N}=\mathbf{5 6})$ & 34 & 5 & 5 & 7 & 4 & 1 & \\
\hline
\end{tabular}

$96 \%$ of students who did not complete the course did not complete a single end-of-course case study assessment.

Table 12. Completion of end-of-course case studies by students who did not complete the course from June 2019 to June 2020 ( $N=56)$.

\begin{tabular}{|l|l|l|l|l|l|l|l|l|l|l|l|}
\hline Number of case studies completed & 0 & 1 & 2 & 3 & 4 & 5 & 6 & 7 & 8 & 9 & 10 \\
\hline Number of students (N = 56) & 54 & & 1 & & 1 & & & & & \\
\hline
\end{tabular}

Although it has been suggested that the course's assessment methods merely assess low-level knowledge and are unable to determine whether the course's learning outcomes have been met, they are nonetheless an integral part of the course, included to help students 'consolidate [their] learning'. Although no claims can be made about any differences in knowledge and understanding between students who completed the assessments and those who did not, the latter group choose not to engage with a significant element of the course. Owing to the limited learning analytics data, nothing is known about how students are engaging with the remaining course content, whether they are watching the videos, engaging with the stop-and-think exercises, and so on. With careful consideration, prudent use of learning analytics data can be used to inform revisions to the course's learning design (Joksimović et al., 2019; Mangaroska \& Giannakos, 2019).

As course evaluation data is only collected from students who request a Certificate of Completion, we do not have these non-completing students' responses to the course evaluation. It would be useful to know why they chose not to complete the assessment aspects of the course, as well as hear their views of the course more broadly. Unfortunately, getting information from students who have left a course is often difficult (Willging \& Johnson, 2009). Although it goes against the grain of the 'light touch' design, the use of learning analytics could identify students who are 'at risk' of not completing the course, which could trigger a member of the Online Learning Support Team contacting these 'at risk' students. Lack of communication and social interaction between 'teachers' and students is a significant factor in why students withdraw from online courses (van Ameijde et al., 2018). 


\section{Suggestions for improving the existing course:}

- Consider how student learning analytics data could be used to inform the course design and support student learning. This requires collecting data that is designed to answer specific questions.

\section{Summary}

On the basis of the available data, we are not able to say that the course adds to what students know and understand, or whether they can apply any new knowledge and understandings to their workplaces. It is highly likely that students have gained new knowledge and understandings, because as Hattie (2009) has shown, just about every educational intervention has a positive effect on achievement. This finding is reinforced by a more recent systematic review of the effect of e-learning on clinician behaviour and patient outcomes, where e-learning (not surprisingly) was found to be superior to receiving no instruction (Sinclair et al., 2016).

More importantly, we are unable to say whether any new knowledge or understandings gained through completing the course influence clinical supervisors' behaviours in their workplaces (the ability to perform a targeted skill for which the intervention was designed).

In the Methods section, we drew attention to the conceptual and practical difficulties of evaluating behaviour change and the application of knowledge and understanding to the workplace. Demonstrating the CSO course's effectiveness, beyond self-reported claims of applying what has been learnt to day-to-day practice remains a challenge, not just for this course, but for most e-learning. So, we must remain sceptical of the strong claims from course evaluation respondents that they applied new knowledge to their day-to-day practice. 


\section{The cost-effectiveness of the course: Return on investment}




\section{Overview}

The highest level of Rossi, Lipsey, and Freeman's (2004) evaluation hierarchy is 'Assessment of program cost and efficiency'. Sophisticated analyses that require specialist knowledge and skills, such as cost-benefit and costeffectiveness analyses were beyond the scope of the evaluation ${ }^{22}$. In planning this aspect of the evaluation, we had a more modest focus, an examination of return on investment, which looks at the income generated through course fees relative to the cost of developing and implementing the course.

\section{Development cost evaluation}

We were unable to uncover the true costs of developing the course or obtain an accurate account of operating costs. In regards to the former, we were advised that creating the content involved significant 'out of hours' work that was not quantified. With respect to the latter, the ongoing support offered to the course's students is not funded through a dedicated employee, but through the Online Learning Support Team who service multiple courses. It was not feasible to put a cost on dealing with the 'student inquiries' that were discussed in the Case reports section. None the less, a broad discussion of the income generated through course fees against the estimated cost of developing the course produces some useful insights and raises some pertinent questions for future consideration.

Table 13 lists the estimated total cost for developing the course as $\$ 17,950.00$ (Mobile Learning Unit, 2018), based on the production of 10 tutorials and 25 case studies, rather than the six tutorials and 10 case studies that were produced.

\begin{tabular}{|l|l|}
\hline \multicolumn{2}{|c|}{$\begin{array}{c}\text { Table 13. Estimated Clinical Supervision Online course development cost } \\
\text { (Mobile Learning Unit, 2018). }\end{array}$} \\
\hline Items & Cost (AUD\$) \\
\hline Project management & 4200 \\
\hline Content production and development & 12300 \\
\hline System setup & 900 \\
\hline Total & 17950 \\
\hline
\end{tabular}

The Department of Medical Education did not have to outlay any capital to cover the Mobile Learning Unit's project management costs. The Mobile Learning Unit receives forty per cent of the course fees until their development fees are reimbursed, with the Department of Medical Education receiving the remaining sixty per cent. At that point, there is 20/80 per cent split in favour of the Department of Medical Education, with the Mobile Learning Unit's share contributing to ongoing operating costs.

Table 14 shows that with the worst-case estimated market size of 50 enrolments a year, the estimated course development costs would have been paid off with the proposed course fee of $\$ 500.00$, or nearly paid-off with the actual course fee of $\$ 350.00$. (Table 11 indicates that $40 \%$ of the revenue is equally split between the Mobile Learning Unit and the Melbourne Medical School.)

\footnotetext{
${ }^{22}$ For example, the hope is that the course will make clinical supervisors more effective and efficient. A cost-benefit analysis would try and convert course outcomes into monetary estimates, assuming that a clinical supervisor who has completed the course is more productive than one who has not; perhaps being able to provide higher quality education in a shorter period of time Levin (2005b). A cost-effectiveness analysis might compare the efficiency of the CSO course with another course that has similar goals and measures of outcome (Levin, 2005a). For example, in an earlier footnote it was stated that the CSO course was a re-working of content from a four-day face-to-face course.
} 
Table 14. Estimated annual market size (adapted from Mobile Learning Unit, 2018)

\begin{tabular}{|c|c|c|c|c|}
\hline $\begin{array}{c}\text { Enrolments } \\
\text { (per year) }\end{array}$ & Total income & Return to MMS (20\%) & Return to MLU (20\%) & Return to DME (60\%) \\
\hline $\mathbf{5 0}$ & $25,000^{\mathrm{a}}(17,500)^{\mathrm{b}}$ & $5000(3,500)$ & $5000(3,500)$ & $15000(10,500)$ \\
\hline $\mathbf{7 0}$ & $35,000(24,500)$ & $7000(4,900)$ & $7000(4,900)$ & $21000(14,700)$ \\
\hline $\mathbf{1 0 0}$ & $50,000(35,000)$ & $10000(7,000)$ & $10000(7,000)$ & $30000(21,000)$ \\
\hline
\end{tabular}

a Return on investment based on course fee of $\$ 500.00$.

${ }^{b}$ In parentheses, return on investment based on course fee of $\$ 350.00$.

By October $8^{\text {th }} 2020$, the CSO course had enrolled 209 students, generating revenue of $\$ 46,932.00$, after removing GST. This works out an average course fee of about $\$ 250.00$, somewhat below the advertised fee of \#350.00. Bulk purchases of the course can be negotiated at a discounted rate.

It might, therefore, be reasonable to claim that the course fees have covered any development costs and started to generate an income for the Department of Medical Education. With no academic inquiries being received to date, the impost on the Course Director has been negligible, underscoring the assumption that once developed, a 'light touch' course involves minimal educator time.

Neither do the visible operating costs appear to be onerous to the Mobile Learning Unit. There has been about one student inquiry a week (see Case reports section), no review meetings have been arranged or feedback reports provided, nor have ongoing marketing costs been incurred. However, the Mobile Learning Unit has incurred other costs, such as the transfer of the course to the new Student Learning Portal.

Although the course is exceeding the highest estimated number of annual enrolments per year, a significant evaluation metric, it was described as a 'stagnant offering', and disappointment was expressed about the small or low number of enrolments.

Certainly, 204 students is insignificant when considered against the estimated market size of 19,370 individuals. (If enrolments remain steady, it would take about 130 years for the estimated market to complete the course.) This raises a number of inter-related questions, which are related to assumptions in the original proposal.

- Is the estimated market size accurate?

- Are there more competitors than originally envisaged?

- Is the price point for the course set at the right level?

- Has the course been marketed effectively?

The estimated market size of 19,370 individuals is five per cent of the estimated total market. (The original proposal document offers no information as to how the total market size was reached.) Royse (n.d.-a) states that between one and five per cent of a total market is ever likely to do a course. No rationale is offered for using the upper limit, rather than the lower one, which would give an estimated market size of 3,874 students.

Not only could the market size be smaller, but it is likely that the competitors for the pool of students is much larger than was initially declared. With hindsight, the competitor analysis could have been more thorough. A cursory internet search will reveal many more courses, and there are many more 'in-house' offerings that will not be uncovered by this search strategy. For example, the ModMed Institute in South Australia offer a fee-paying course (\$275.00) entitled Mastering Supervision. It consists of eight modules, with a study time comparable to the CSO course. Its primary audience is General Practice supervisors, and the course is similarly recognised as an accredited activity by both General Practice Colleges. Less visible is the professional development offered by the nine Regional Training Providers contracted to deliver the Australian General Practice Training program. They all offer professional development for their clinical supervisors, who are paid for attending, which includes foundational courses that in some cases are prerequisites to becoming a clinical supervisor. 
A superficial market analysis may also result in a 'price point' for the course that is less than optimum. Some offerings listed by competitors in Table 4 are free ${ }^{23}$. The initial higher course fee of $\$ 500.00$ was said to be comparable to other courses offered by the Mobile Learning Unit, often targeted at high-earning doctors, who may also have access to funding for professional development. The lower, established course fee of $\$ 350.00$ acknowledges that the course is aimed at clinicians across the breadth of health professions education, including those that are less well-paid than doctors, and makes allowance for professional development that is self-funded. Additionally, completing the course is unlikely to create opportunities for higher earning potential on the part of the participant. Where this is the case, courses may be able to charge more. In some situations, for example, in general practice, taking on students and vocational trainees may result in a loss of income (Laurence et al., 2014).

There were different perspectives on the current course fee, viewing it as 'competitive', 'a stab in the dark', and reflecting a 'let's see how it goes' strategy. The price has remained unchanged since the course's launch, although organisations can negotiate with the Mobile Learning Unit to agree a discounted fee for multiple purchases.

A further possible reason for the course not meeting expectations is that not enough resources have been spent marketing it or the wrong type of marketing has been used. The CSO course was launched with what Enders (n.d.) terms a moderate promotional campaign (e.g., website design, social media advertisements) and since then, no money has been spent marketing the course and there have been no review meetings to appraise promotional strategies, verify marketing responsibilities, or agree a budget. It may be the case that there is lack of clarity in terms of responsibility for marketing the course. The original project proposal identifies 'Ongoing marketing to ensure yearly enrolments' as a MLU responsibility (Mobile Learning Unit, 2018) whilst a more generic document identifies the 'host' Department as being responsible for ongoing marketing (Mobile Learning Unit, 2018, n.d.-b). As Royse (n.d.-a) writes, "Without effective marketing that generates leads, the course will not be visible to prospective students" (bold added). The CSO course is aimed at 'all clinicians who teach' but given that the course sits within the Melbourne Medical School, it may be less visible to Allied Health clinical supervisors or not perceived as being relevant to them. It may be necessary to educate this segment of the market, to help them understand how the course is relevant to them (Enders, n.d.).

\section{Summary}

In summary, it is likely that the course has reached a point where there has been a return on investment, and that it is generating a small amount of income for the Department of Medical Education and the Mobile Learning Unit. There remain some unresolved questions about whether the course in its present form could be a stronger performer in terms of generating income, or whether some of the initial expectations were overly ambitious.

Suggestions for improving the existing course:

- Consider undertaking a new and more through market analysis

- Explore the place of the CSO course within the current Department of Medical Education and Melbourne Medical School clinical education professional development offerings.

- Review the marketing strategy for the course, including responsibilities for marketing, and consideration of the potential for the CSO course to be included in specialist medical college professional development. The clinical schools associated with the Melbourne Medical School also presents another opportunity to expand the reach.

- Review the cost of the course, including consideration of a lower price point to expand access for the breadth of health professions educators.

\footnotetext{
${ }^{23}$ Up until the end of 2020, The Open University in the United Kingdom offer a free online course called Facilitating Learning in Practice, which explored the principles and best practices underpinning mentorship. Although the course had a strong nursing focus, which could contribute towards the Nursing and Midwifery Council's approved Mentorship program, the authors claimed that the content could be applied to many workplace environments. Participants earnt an Open University digital badge for completing the course's required 24 hours of study.
} 


\section{Discussion}




\section{Overview}

This evaluation sought to explore the genesis, design, implementation and outcomes of a mobile learning application as a professional development opportunity for clinical supervisors. Data informing the evaluation were drawn from interviews with and written responses from, key stakeholders; analysis of available learning analytics data; analysis of post-course completion data; and a review of the instructional design and delivery of the CSO course. The evaluation has highlighted a number of strengths of the CSO course offering and also identified opportunities for further consideration by stakeholders. In describing the key messages emanating from the evaluation, we propose a series of questions related to the role of stakeholders, responsibility for the professional development of clinical supervisors and whether the CSO course offering meets a need, and conclude with possible future directions for the course.

\section{How well does the Mobile Learning Unit discharge its responsibilities?}

Getting the CSO course 'up and running' was a collaborative effort between the Department of Medical Education and the Mobile Learning Unit that appears to have worked well. Drawing on project management expertise, the Mobile Learning Unit are clear about what they are and are not responsible for (Mobile Learning Unit, 2018, n.d.-b). In addition to managing the 'project build' and publishing the course content, the Mobile Learning Unit have an ongoing responsibility for ensuring the course is delivered and supporting continuous improvements. The evaluation findings suggest that the former, through managing student communications, processing course payments, sending introductory emails to students, and providing ongoing technical assistance is done well, whilst improvements can be made in how the Mobile Learning Unit supports continuous improvements to the CSO course. Transferring the course to the Student Learning Portal, a Mobile Learning Unit initiative, has improved the course's delivery, look, feel and interactivity. This evaluation also highlights a number of limitations with the mobile learning platform used to host the CSO course, particularly the availability of 'trustworthy' learning analytics data to inform changes to the course, or indeed the platform itself.

During our data collection period, some 18 months after the course was launched, there had been no review meetings with the Department of Medical Education to discuss the implications of student feedback reports, reappraise the content, or reassess the approach to marketing the course. This may no longer be the case as of the date of this report's publication, as the act of asking questions about the absence of these activities, drew stakeholders' attention to the need to convene a review meeting. Reviewing student feedback may also have highlighted both the shortcomings of student data within the CRM system and the current feedback-seeking process, with the course evaluation being of limited value in providing meaningful insights into whether the course is impacting on students' supervisory practices. Based on these observations, we suggest that a review of the marketing of the CSO course be undertaken to understand the strategies that were successful in promoting uptake and those that resulted in little or no value. Further, we suggest that the Mobile Learning Unit and Melbourne Medical School (with the Department of Medical Education) agree on marketing responsibilities, which then informs commitment of resources for the marketing of the CSO course.

\section{Who is responsible for clinical supervisor professional development?}

To date, we know little about the make-up and nothing about the motivations of the students who have enrolled in and completed the course. We do know that some organisations have made bulk purchases of the course, which suggests that those organisations are taking some responsibility for making professional development available for their clinical supervisors, but don't know whether this is the entirety of their professional development or part of a larger program. Without the 'missing' demographic information we additionally don't know how many students are enrolling on the CSO course as a more personal initiative, and their motivations for doing so.

Although some health professions require clinical supervisors to demonstrate supervisory competencies, such as the Nursing and Midwifery Council in the UK, this is not a universal requirement. For many clinical supervisors, this is in stark contrast to the requirements for maintaining registration as a medical practitioner, where it is mandated to participate in professional development that maintains, updates and enhances their knowledge and skills as a health professional. That said, Codes of Conduct for registered health professions in Australia support the notion of professional development as a teacher as being a component of good practice. For example, the Medical Board of 
Australia Code of Conduct states that good medical practice involves, 'Seeking to develop the skills, attitudes and practices of an effective teacher, whenever you are involved in teaching' (Medical Board of Australia, 2020, p. 31).

For many health professionals becoming a clinical supervisor is an extra-role, whose importance in maintaining patient safety and educating the next generation of health professionals is reflected in common metaphors used to describe it. The Royal Australian College of General Practitioners (2017) write that, "Supervisors are the backbone of the general practice training program" (p.19, bold added) whilst Weston (2018) writes in relation to nursing that, "Clinical instruction for students is a cornerstone of nursing education, a component essential to preparation of students for the role of nurse" (p.158, bold added) The use of these metaphors is intended to convey that supervisors are a key resource upon which the training of future health professionals is based.

If we accept this argument, then the onus is not on the individual employee but on health care organisations to provide clinical supervisors with the requisite support and educational experiences to fulfil their role competently (Dunker, 2014). Yet, despite acknowledging supervisors' importance, Kinsella (2008) claims that organisations can also forget that they are the 'cornerstone' of training. A narrow focus on online education's potential to overcome geographical constraints or the difficulties of releasing staff from their day-to-day work may marginalise other important features of learning design and organisational responsibilities.

McColgan and Rice (2012) point out that a restricted focus on the aforementioned key 'selling points' of online learning - access, convenience, and flexibility - can come at a cost to health care workers. Rather than quarantining time for professional development at work (Monash Health, 2013), flexibility may create pressure for clinical supervisors to complete clinical supervision training in their own time. Zahner (2006) reported that 19\% of the online modules in the Partnerships for Learning Community Health Nursing program were completed in the participants' own time. In a related study Larsen and Zahner (2011) reported that only 31 out of 133 clinical supervisors (23\%) who started the online educational program completed it, with 'being overwhelmed at work' given as a common reason for not completing it.

\section{Is the CSO course a reasonable 'solution' to the problem of supervisor professional development?}

From a learning design perspective there is much to like about the CSO course and the outcome of the assessment against the standards of the QOCI rubric suggest that an evolutionary approach - making incremental changes - could improve the course whilst retaining its existing 'light touch' format. Yet, throughout the report, we have posed a series of related questions as to whether the CSO course represents a good or reasonable 'solution' to the problem of clinical supervisors' professional development. Given that we know next to nothing about whether the CSO course impacts on clinical supervisor behaviours, the commentary that follows is inevitably speculative.

We flagged that drivers for the development of many of the online courses that we reviewed were related to discourses of 'access', 'convenience' and 'flexibility'. However, online courses for clinical supervisors have to be more than just a more convenient way of accessing content, they also need to show that resulting new knowledge and skills are applied in workplaces in a way that impacts positively on the learners they supervise, and that changes to their practices are sustained over time (Debattista, 2018).

We reported that informants expressed disappointment with the number of students who have enrolled to date. At present, we do not know whether this is something to do with the course itself or related to how the course is marketed. Potential students are currently able to sample a tutorial before enrolling. In one report we received, we calculated that 129 people out of 146 (88\%) who sampled the course did not go on to enrol in it. It would be useful to know why these potential students chose not to enrol as we might infer that they did not perceive the CSO course as the 'solution' to their training needs. It would also be helpful to know why 39 per cent of students did not complete the course, as at some point they decided that the remaining content was not part of the 'solution' to their training needs. Neutral comments about the course from people who have sampled it, or negative word-of-mouth reviews from students who do not complete the course may close-off potential enrolments or result in reputational harm, both to the course itself and by association the university.

High levels of non-completion have been found in relation to other online clinical supervision courses. For example, Tai et al. (2016) reported that $67 \%$ of participants who started the core module in the Clinical Supervision Support Across Contexts (ClinSSAC) program did not complete all the activities within the module. The companion report noted 
that in comparison to face-to-face modules, "The online modules appear to have had more difficulty in gaining 'traction'", adding that, "There appears to be high levels of 'good intentions' but difficulty in completing the package once enrolled" (Monash Health, 2013, p.32).

The ClinSSAC study involved relatively large numbers, with 978 clinicians participating in a face-to-face introductory module to clinical supervision and 672 accessing an equivalent online module. Of note here is that the most frequent comments about what worked well in the face-to-face modality related to a theme of 'interaction, discussion, practical activities, sharing experiences' (519 comments); characteristics that are missing in the CSO course's 'light touch' design. We also noted earlier that the lack of communication and social interaction between 'teachers' and students is a significant factor in why students withdraw from online courses (van Ameijde et al., 2018). In fact, many of the reviewed articles highlighted similar-sounding factors as being important in effective professional development; connecting, engaging, collaborating, and sharing knowledge with colleagues (Archer et al., 2020; Myrick et al., 2011).

The factors that were consciously excluded in the CSO course's 'light touch' design were highlighted by the application of the QOCI rubric, where 10 out of 11 items in the 'Communication, interaction, and collaboration' category were judged as 'not applicable'. According to the standards of the QOCI rubric, a quality online course should at least consider activities that foster student-to-student and student-to-instructor interactions. Unfortunately, the inclusion of such interactions changes a course from a 'light touch' design to a 'high touch' one and impacts on the ability to scale the reach of the course (Royse, n.d.-a). The inference or 'working theory' that we can draw from these articles is that including student-to-student interactions and student-to-tutor interactions may lessen drop-outs and noncompletions and help to build students' new knowledge and understandings of the clinical supervisor role. Few course evaluation respondents indicated in their free-text responses that interaction with other students and educators was something that was missing from the CSO course. Students who enrol on the course should be acutely aware of its solo, self-directed nature and interaction with others is not a consideration. Conversely, individuals who did not complete the CSO course may have done so due to a lack of interaction with others.

The absence of student-to-student and student-to-instructor interactions may also cause some potential students to baulk at paying $\$ 350.00$. Although oversimplistic to compare the CSO course with a book; both only require students and readers to interact with the respective content, acknowledging that a book can be as engaging as an online course for some individuals, and the converse with others. Academic books and study guides often come with questions for readers to reflect on and it is increasingly common for academic books to be published as enhanced e-texts with interactive features. 'Essential skills for a medical teacher' (Harden \& Laidlaw, 2017), 'Practice-based teaching' (Hays, 1999), 'Teaching in your office' (Alguire et al., 2008), 'The inner apprentice' (Neighbour, 2005), and 'Teaching in the hospital' (Wiese, 2010) are examples of books aimed at clinical supervisors that retail for about $\$ 60.00$, which one can also access anywhere at any time. Like the CSO course, some of these books are generic, whilst others are tailored for particular settings (e.g., 'the hospital') or specialties (e.g., general practice). It is likely that potential students will have preferences for a universal or more tailored course. It would be useful to know more about these preferences, and whether students found it easy to translate the CSO course to their particular contexts. Although the ClinSSAC program had a core module, fifteen discipline-focused modules were developed to reflect the specific supervisory demands that exist within different disciplines and in different work settings (Monash Health, 2013). It may be that some people exclude the CSO course as the 'solution' to their training needs on the basis of 'cost' or its generic nature.

Some other learning design features, deliberately absent in the CSO course, may similarly help the course to have an enhanced impact, particularly in relation to the application of new knowledge and understandings to the workplace. A review of the public health workforce's preferred modalities for receiving professional development found that respondents generally preferred a 'learning by doing' approach; that is, time for the practical application of content (Archer et al., 2020). We noted that in its current form, that there are no learning activities that are specifically designed to help students improve their skills, nor are there any explicit learning activities that require students to apply their knowledge and understanding to the workplace. 'Role play', an obvious 'learning by doing' activity is possible when there are interactions with other students or educators. The Online Clinical Supervision resource described by McColgan and Rice (2012) included a series of activities that involved observing an actual nursing supervision session and answering some reflective questions, prior to structuring students' first clinical supervision session in practice. In a related vein, Tai et al. (2016) reported that continuing support for students, likely ongoing interactions with peers or educators, is additionally important in developing clinical supervisors' skills. 
In the aforementioned public health workforce review, online training with a complementary in-person element was the most popular modality for professional development (Archer et al., 2020) and a meta-analysis undertaken on behalf of the US Department of Education found a significant increase in performance for blended learning but not for pure online learning (Means et al, 2013 in Debattista, 2018). As above, a blended learning design, learning by doing, and ongoing support move a professional development program into 'high touch' territory. In the section on 'future possibilities' that follows, we outline an interest in supplementing the extant CSO course with some of these learning design features through a project with the Melbourne Academic Centre for Health (MACH).

These ideas about learning design also question whether the 'theory of change' that we think underpins the course's hoped for improvements in workplace performance - the idealised self-directed learner - holds up under scrutiny, and might be complemented by socio-cultural approaches to teaching and learning that are reflected in these findings (see Kaufman \& Mann, 2014).

We have implied that the CSO course is unlikely to realise the depth of achievement implied in the course aims and learning outcomes, of giving clinicians the understanding and skills to create learning environments within which learners can thrive. This is, in part, due to the limitations of the 'light touch' design but more significantly due to the insufficient 'volume of learning' built into the course. Rather, the CSO course outwardly appears to be an entrée into clinical supervision or a strategy to reinforce or revise one's individual clinical supervision approach. We believe that the depth of achievement required of an effective clinical supervisor is indicative of a high degree of difficulty that requires a greater 'volume of learning'. Clinical supervisors will, of course, learn 'on the job' through the experience of supervising, but this needs to be complemented by ongoing professional development. As dual professionals, both the clinical and educator roles should be subject to continuous improvement (Stoddard \& Brownfield, 2016). Extending the reflective stance of the competent medical professional to the clinical supervisor role would indicate an ongoing commitment to critically examining one's supervisory practices in order to improve them. Mills (2018) suggests that this is a commitment to the principle that, as an educator, "one is always far from the ideal but is striving toward it" (p.17). Such a view is consistent with framing professional development as 'becoming' rather than 'being', where becoming an effective clinical supervisor is always a 'work in progress' rather something one has mastered (Bleakley, 2011).

From this perspective, the CSO course is part of the patchwork of professional development 'solutions' that aspire to meet the training needs of 'clinicians who teach' and/or supervise learners', but at best is a foundational course or 'starting point'.

\section{Future possibilities: Learning design, research, and evaluation}

This evaluation of the CSO course was undertaken with a formative orientation, and as such, the report contains numerous suggestions for the course team to consider, which may improve the existing 'light touch' learning design. Any changes to the learning design lend themselves to future evaluative work.

We also highlighted significant gaps in student perceptions of the course, which are not captured by the current online course evaluation. For example, we do not know why a large number of students do not complete the case studies and feedback is narrowly collected from students that complete the course. Gathering missing information will require changes to the way that information is currently collected from students.

Some well-targeted market research might plug some major holes in the 'marketing umbrella'. We have little information about who is enrolling for the CSO course; how they found out about the course; why most people who sample the course do not go on to enrol; how the current 'price point' is perceived, and so on. Answering such questions may inform how the course is marketed and feed into discussions about learning design.

We still no next to nothing about the course's impact, particularly whether students gain any new knowledge and understandings, and whether they can apply this knowledge and understandings to their workplaces. Evaluating impact requires overcoming some challenging methodological problems and necessitates moving beyond self-reports. There is some interesting evaluative work to be done here, such as developing valid pre- and post-measures of knowledge about clinical supervision or examining changes to supervisory practice. Such consideration inevitably raises questions about cost.

In addition, some foundational work also seems necessary. In this regard we highlighted the lack of agreement about the competency requirements of clinical supervisors, or the depth of achievement required of an effective supervisor. 
We also asked whether a short course, 'light touch' design, without any interactions between students and tutors could achieve the depth of achievement implied in the course aims and learning outcomes; noting that such additions moved the course into 'high touch' territory. Yet adding in these 'high touch' features are documented in a proposal developed by the Excellence in Clinical Teaching team in the Department of Medical Education for the Melbourne Academic Centre for Health (MACH) (Excellence in Clinical Teaching Team, n.d.). In this proposal, staff who have completed the CSO course, who work for organisations that are members of MACH will be able to join a series of interactive webinars. The webinars build-in interactions between other clinical supervisors and expert medical educators, discussions of practice issues, and so on. Although a naïve comparison of the 'light touch' CSO course with an extended 'high touch' program is "futile" (Cook, 2005, p.541), it certainly provides a new evaluation opportunity that can built upon the foundational work that underpins this report. 


\section{References}

Alguire, P. C., DeWitt, D. E., Pinsky, L. E., \& Ferenchick, G. S. (2008). Teaching in your office: A guide to instructing medical students and residents (2nd ed.). ACP Press.

Archer, A., Berry, I., Bajwa, U., Kalda, R., \& Di Ruggiero, E. (2020). Preferred modalities for delivering continuing education to the public health workforce: a scoping review. Health Promotion and Chronic Disease Prevention in Canada: Research, Policy and Practice, 40(4), 116-125. https://doi.org/10.24095/hpcdp.40.4.03

Australian Qualifications Framework Council. (2013). Australian Qualifications Framework (2nd ed.). Australian Government Department of Education, Skills and Employment.

Bleakley, A. (2011). Becoming a Medical Professional. In L. Scanlon (Ed.), "Becoming" a Professional (pp. 129-151). Springer.

Boydell, T., \& Leary, M. (1996). Identifying Training Needs. Institute of Personnel and Development.

Cirigliano, M. M., Guthrie, C. D., \& Pusic, M. V. (2020). Click-level Learning Analytics in an Online Medical Education Learning Platform. Teaching and Learning in Medicine, 32(4), 410-421. https://doi.org/10.1080/10401334.2020.1754216

Cook, D. A. (2005). The Research We Still Are Not Doing: An Agenda for the Study of Computer-Based Learning. Academic Medicine, 80(6), 541-548.

Creswell, J. (2013). Qualitative inquiry \& research design: Choosing among five approaches. (3rd ed.). Sage Publications, Inc.

Dalton, L., Bull, R., Taylor, S., Galbraith, K., Marriott, J., \& Howarth, H. (2007). Evaluation of the national pharmacy preceptor education program. Australian Journal of Rural Health, 15(3), 159-165. https://doi.org/10.1111/j.1440-1584.2007.00878.x

Davis, D. A., Mazmanian, P. E., Fordis, M., Van Harrison, R. R., Thorpe, K. E., \& Perrier, L. (2006). Accuracy of physician self-assessment compared with observed measures of competence: A systematic review. JAMA, 296(9), 1094-1102. https://doi.org/10.1001/jama.296.9.1094

Debattista, M. (2018). A comprehensive rubric for instructional design in e-learning. The International Journal of Information and Learning Technology, 35(2), 93-104. https://doi.org/10.1108/IJILT-09-2017-0092

Dunker, K., S. (2014). Development and preliminary testing of an on-line continuing education program for adjunct clinical nursing faculty. International Journal of Nursing, 1(2), 7-21. https://doi.org/10.15640/ijn.v1n2a2

Enders, R. (n.d.). Understanding the business of online learning. Mobile Learning Unit, Melbourne Medical School, The University of Melbourne.

Excellence in Clinical Teaching Team. (n.d.). MACH Teach: Building clinical educator capacity across the health professions. Department of Medical Education, Lelbourne Medical School, The University of Melbourne.

Forster, N. (1994). The analysis of company documentation. In C. Cassell \& G. Symon (Eds.), Qualitative methods in organizational research: A practical guide (pp. 147-166). Sage Publications.

Goyder, J. (2008). Nonresponse. In P. J. Lavrakas (Ed.), Encyclopedia of Survey Research Methods (pp. 1-6). https://doi.org/10.4135/9781412963947

Harden, R. M., \& Laidlaw, J. M. (2017). Essential skills for a medical teacher: An introduction to teaching and learning in medicine (2nd ed.). Elsevier.

Hattie, J. (2009). Visible learning: A synthesis of over 800 meta-analyses relating to achievement. Routledge.

Hays, R. (1999). Practice-based teaching: a guide for general practitioners. Eruditions Publishing.

Health Workforce Australia. (2010). Clinical supervisor support program: Discussion paper.

Health Workforce Australia. (2014). National Clinical Supervision Competency Resource. Health Workforce Australia.

Honderich, T. (Ed.). (1995). The Oxford Companion to Philosophy Oxford University Press.

Huber, M. T., \& Hutchings, P. (2004). Integrative Learning: Mapping the Terrain. Association of American Colleges and Universities.

Illinois Online Network. (1998-2019). Quality Online Course Initiative Rubric. University of Illinois. Retrieved April 8th, 2020, from https://www.uis.edu/ion/resources/qoci/

Joksimović, S., Kovanović, V., \& Dawson, S. (2019). The Journey of Learning Analytics. HERDSA Review of Higher Education, 6, 37-63.

Kadirvelu, A., \& Gurtu, S. (2015). Integrated Learning in Medical Education: Are Our Students Ready? Medical Science Educator, 25(4), 549-551. https://doi.org/10.1007/s40670-015-0172-0

Kaufman, D. M., \& Mann, K. V. (2014). Teaching and learning in medical education: How theory can inform practice. In T. Swanwick (Ed.), Understanding medical education: Evidence, theory and practice. (2nd ed., pp. 7-29). Wiley-Blackwell.

Kinsella, P. (2008). GP supervisors: their professional development and involvement in assessment. Australian Family Physician, 37(1/2), 66-67. 
Kyeong-Ju, K., \& Engelhard, C. (2014). Using the Constructivist Tridimensional Design Model for online Continuing Education for Health Care Facility. American Journal of Distance Education, 28(1), 39-50. https://doi.org/10.1080/08923647.2014.868754

LaDonna, K., Taylor, T., \& Lingard, L. (2018). Why Open-Ended Survey Questions Are Unlikely to Support Rigorous Qualitative Insights. Academic Medicine, 93(3), 347-349. https://doi.org/10.1097/ACM.0000000000002088

Larsen, R., \& Zahner, S. J. (2011). The Impact of Web-delivered Education on Preceptor Role Self-Efficacy and Knowledge in Public Health Nurses. Public Health Nursing, 28(4), 349-356. https://doi.org/10.1111/i.15251446.2010.00933.x

Laurence, C. O., Coombs, M., Bell, J., \& Black, L. (2014). Financial costs for teaching in rural and urbam Australian general practices: Is there a difference? Australian Journal of Rural Health, 22, 68-74. https://doi.org/10.1111/ajr.12085

Levin, H. M. (2005a). Cost effectiveness. In S. Mathison (Ed.), Encyclopedia of Evaluation (pp. 90). Sage. https://doi.org/10.4135/9781412950558

Levin, H. M. (2005b). Cost-benefit analysis. In S. Mathison (Ed.), Encyclopedia of Evaluation (pp. 87-90). Sage. https://doi.org/10.4135/9781412950558

Mangaroska, K., \& Giannakos, M. (2019). Learning Analytics for Learning Design: A Systematic Literature Review of Analytics-Driven Design to Enhance Learning. IEEE Transactions on Learning Technologies, 12(4), 516-534. https://doi.org/10.1109/TLT.2018.2868673

McColgan, K., \& Rice, C. (2012). An online training resource for clinical supervision. Nursing Standard, 26(24), 35-39.

Medical Board of Australia. (2020). Good medical practice: code of conduct for doctors in Australia. Australian Health Practitioner Regulation Agency,. Retrieved April 13, 2021, from https://www.medicalboard.gov.au/CodesGuidelines-Policies.aspx

Mills, G. E. (2018). Action research: A guide for the teacher researcher (6th ed.). Pearson.

Mobile Learning Unit. (2018). Project prpoosal. Mobile Learning Unit, Melbourne Medical School, The University of Melbourne.

Mobile Learning Unit. (n.d.-a). Clinical Supervision Online (Brochure). Mobile Learning Unit, Melbourne Medical School, The University of Melbourne.

Mobile Learning Unit. (n.d.-b). eLearning Made Easy (Brochure). Mobile Learning Unit, Melbourne Medical School, The University of Melbourne. Retrieved November 27th, 2020, from https://medicine.unimelb.edu.au/about/mobile-learning-unit\#course-development

Monash Health. (2013). Clinical supervision support across contexts (ClinSSAC): Final project report. Victoria State Government Department of Health and Monash University (The Health Professions Education and Educational Research Team (Health PEER)).

Moore, M. G. (1989). Editorial: Three types of interaction. American Journal of Distance Education, 3(2), 1-7. https://doi.org/10.1080/08923648909526659

Myrick, F., Caplan, W., Smitten, J., \& Rusk, K. (2011). Preceptor/mentor education: A world of possibilities through elearning technology. Nurse Education Today, 31(3), 263-267. https://doi.org/10.1016/j.nedt.2010.10.026

Neighbour, R. (2005). The inner apprentice (2nd ed.). CRC Press.

Nichols, M. (2020). Transforming Universities with Digital Distance Education. Routledge. https://doi.org/10.4324/9780429463952

Ogrinc, G., Armstrong, G. E., Dolansky, M. A., Singh, M. K., \& Davies, L. (2019). SQUIRE-EDU (Standards for QUality Improvement Reporting Excellence in Education): Publication Guidelines for Educational Improvement. Academic Medicine, 94(10), 1461-1470. https://doi.org/10.1097/ACM.0000000000002750

Olanrewaju, O. S., \& Thistlethwaite, J. (2013). A systematic review of faculty development activities in family medicine. Medical Teacher, 35, e1309-e1318. https://doi.org/10.3109/0142159X.2013.770132

Patton, M. Q. (2008). Utilization-focused evaluation (4th ed.). Sage Publications, Inc.

Phillips, J. M. (2006). Preparing preceptors through online education. Journal for Nurses in Staff Development, 22(3), 150-156.

Rice, S., \& McKendree, J. (2014). e-Learning. In T. Swanwick (Ed.), Understanding Medical Education: Evidence, Theory and Practice (2nd ed., pp. 161-173). Wiley Blackwell.

Rienties, B., Nguyen, Q., Holmes, W., \& Reedy, K. (2017). A review of ten years of implementation and research in aligning learning design with learning analytics at the Open University UK. Interaction Design and Architecture(s) Journal, 33, 134-154. http://oro.open.ac.uk/51188/

Rossi, P. H., Lipsey, M. W., \& Freeman, H. E. (2004). Evaluation: A systematic approach (7th, Ed.). Sage Publications. Royal Australian College of General Practitioners. (2017). Standards for general practice training (2nd ed.). The Royal Australian College of General Practitioners.

Royse, C. (n.d.-a). Introduction to Development and Delivery of Online and Mobile Learning. Mobile Learning Unit, Melbourne Medical School, The University of Melbourne. 
Royse, C. (n.d.-b). "Light Touch" Online Learning Pedagogy. Mobile Learning Unit, Melbourne Medical School, The University of Melbourne.

Sinclair, P. M., Kable, A., Levett-Jones, T., \& Booth, D. (2016). The effectiveness of Internet-based e-learning on clinician behaviour and patient outcomes: A systematic review. International Journal of Nursing Studies, 57, 70-81. https://doi.org/10.1016/i.ijnurstu.2016.01.011

Steinert, Y., Mann, K., Anderson, B., Barnett, B. M., Centeno, A., Naismith, L., Prideaux, D., Spencer, J., Tullo, E., Viggiano, T., Ward, H., \& Dolmans, D. (2016). A systematic review of faculty development initiatives designed to enhance teaching effectiveness: A 10-year update: BEME Guide No. 40. Medical Teacher, 38(8), 769-786. https://doi.org/10.1080/0142159X.2016.1181851

Steinert, Y., Mann, K., Centeno, A., Dolmans, D., Spencer, J., Gelula, M., \& Prideaux, D. (2006). A systematic review of faculty development initiatives designed to improve teaching effectiveness in medical education: BEME Guide No. 8. Medical Teacher, 28(6), 497-526. https://doi.org/10.1080/01421590600902976

Stoddard, H., \& Brownfield, E. D. (2016). Clinical-Educators as dual professionals: A contemporary reappraisal. Academic Medicine, 91(7), 921-924. https://doi.org/10.1097/ACM.0000000000001210

Tai, J., Bearman, M., Edouard, V., Kent, F., Nestel, D., \& Molloy, E. (2016). Clinical supervision training across contexts. The Clinical Teacher, 13(4), 262-266. https://doi.org/10.1111/tct.12432

Taylor, S., Best, D., Marriott, J., Dalton, L., Bull, R., Leversha, A., Galbraith, K., Howarth, H., Simpson, M., \& Rose, M. (2007). Participant views of an on-line program supporting rural pharmacy preceptors. Focus on Health Professional Education, 9(3), 44-56.

The California State University. (2017). Quality Learning and Teaching (QLT) Instrument. Retrieved April 8th, 2020, from http://courseredesign.csuprojects.org/wp/qualityassurance/qlt-informal-review/

van Ameijde, J., Weller, M., \& Cross, S. (2018). Learning Design for Student Retention. Journal of Perspectives in Applied Academic Practice, 6(2), 41-50. https://doi.org/10.14297/ipaap.v6i2.318

Weston, J. (2018). The Clinical Instructor Program. Nurse Educator, 43(3), 158-161. https://doi.org/10.1097/NNE.0000000000000452

Wiese, J. (2010). Teaching in the Hospital. ACP Press.

Willging, P. A., \& Johnson, S. D. (2009). Factors that influence students' decisions to dropout of online courses [Article]. Journal of Asynchronous Learning Networks, 13(3), 115-127. https://eric.ed.gov/?id=EJ862360

Wong, B. M., \& Headrick, L. A. (2020). Application of continuous quality improvement to medical education. Medical Education, 55, 72-81. https://doi.org/10.1111/medu.14351

Yardley, S., \& Dornan, T. (2012). Kirkpatrick's levels and education evidence. Medical Education, 46, 97-106. https://doi.org/10.1111/j.1365-2923.2011.04076.x

Zahner, S. J. (2006). Partnerships for Learning Population-Based Public Health Nursing: Web-Delivered Continuing Education for Public Health Nurse Preceptors. Public Health Nursing, 23(6), 547-554. https://doi.org/10.1111/i.1525-1446.2006.00595.x 


\section{Appendix A - Quality Online Course Initiative (QOCI) \\ Rubric}


Ratings of the Clinical Supervision Online course on the Quality Online Course Initiative (QOCI) Rubric (Illinois Online Network, 1998-2019)

\begin{tabular}{|c|c|c|c|}
\hline Category & Standard & Characteristic & Rating \\
\hline \multirow{23}{*}{ I. Instructional design } & \multirow{4}{*}{ A. Structure } & 1. Sequence & Meets \\
\hline & & 2. Chunking & Meets \\
\hline & & 3. Purpose & Developing $^{*}$ \\
\hline & & 4. Organisation & Meets \\
\hline & \multirow{2}{*}{$\begin{array}{l}\text { B. Learning goals, objectives, and } \\
\text { outcomes }\end{array}$} & 1. Course goals and objectives & Developing \\
\hline & & 2. Module objectives & Developing \\
\hline & \multirow{9}{*}{ C. Course information } & 1. Description & Meets \\
\hline & & 2. Instructor information & Not applicable ${ }^{*}$ \\
\hline & & 3. Instructional materials & Meets \\
\hline & & 4. Credit hours & Not applicable $^{*}$ \\
\hline & & 5. Content & Meets \\
\hline & & 6. Grading policy & Not applicable \\
\hline & & 7. Calendar & Not applicable \\
\hline & & 8. Technical competencies & Non-existent \\
\hline & & 9. Technical requirements & Developing \\
\hline & \multirow{4}{*}{ D. Instructional strategies } & 1. Multimodal instructional & Not applicable \\
\hline & & 2. Knowledge demonstration & Meets \\
\hline & & 3. Ice breaker & Not applicable \\
\hline & & 4. Presentation & Meets \\
\hline & \multirow{2}{*}{ E. Academic integrity } & 1. Course development & Meets \\
\hline & & 2. Code of conduct & Not applicable \\
\hline & \multirow{2}{*}{ F. Use of multimedia } & 1. Audio files & Not applicable \\
\hline & & 2. Video files & Meets \\
\hline \multirow{11}{*}{$\begin{array}{l}\text { II. Communication, } \\
\text { interaction, and } \\
\text { collaboration }\end{array}$} & \multirow{3}{*}{ A. Activities and opportunities } & 1. Student to student & Not applicable \\
\hline & & 2. Student to instructor & Not applicable \\
\hline & & 3. Student to content & Exceeds $^{*}$ \\
\hline & \multirow{4}{*}{ B. Organization and management } & 1. Types & Not applicable \\
\hline & & 2. Organization & Not applicable \\
\hline & & 3. Access & Not applicable \\
\hline & & 4. Role & Not applicable \\
\hline & \multirow{4}{*}{ C. Group work } & 1. Task & Not applicable \\
\hline & & 2. Formation & Not applicable \\
\hline & & 3. Management & Not applicable \\
\hline & & 4. Delivery & Not applicable \\
\hline \multirow{5}{*}{$\begin{array}{l}\text { III. Student evaluation and } \\
\text { assessment }\end{array}$} & \multirow{2}{*}{ A. Goals and objectives } & 1. Aligned & Not applicable $^{*}$ \\
\hline & & 2. Communicated & Meets \\
\hline & \multirow{3}{*}{ B. Strategies } & 1. Method & Meets $^{*}$ \\
\hline & & 2. Frequency & Meets \\
\hline & & 3. Tools & Non-existent \\
\hline
\end{tabular}




\begin{tabular}{|c|c|c|c|}
\hline Category & Standard & Characteristic & Rating \\
\hline & & 4. Readiness & Developing \\
\hline & & 5. Academic integrity & Not applicable \\
\hline & \multirow{6}{*}{ C. Grades } & 1. Rubric & Meets \\
\hline & & 2. FERPA ${ }^{24}$ & Meets \\
\hline & & 3. Grading scale & Not applicable \\
\hline & & 4. Penalties & Not applicable \\
\hline & & 5. Participation & Meets ${ }^{*}$ \\
\hline & & 6. Extra credit & Not applicable \\
\hline & \multirow{3}{*}{ D. Feedback } & 1. When & Meets \\
\hline & & 2. What & Meets \\
\hline & & 3. How & Meets \\
\hline & \multirow{6}{*}{ E. Management } & 1. Time & Not applicable \\
\hline & & 2. Deadline & Not applicable \\
\hline & & 3. Availability & Not applicable \\
\hline & & 4. Retake & Developing \\
\hline & & 5. Delivery method & Meets \\
\hline & & 6. Submit & Meets \\
\hline \multirow{8}{*}{$\begin{array}{l}\text { IV. Learner support and } \\
\text { resources }\end{array}$} & \multirow{4}{*}{$\begin{array}{l}\text { A. Institutional or program support and } \\
\text { resources }\end{array}$} & 1. Policies & Meets \\
\hline & & 2. CMS support & Meets \\
\hline & & 3. Technical support & Meets \\
\hline & & 4. ADA support ${ }^{25}$ & Non-existent \\
\hline & \multirow{4}{*}{ B. Academic supp } & 1. Glossary & Non-existent \\
\hline & & 2. Orientation & Not applicable \\
\hline & & 3. Resources & Not applicable \\
\hline & & 4. Gradebook & Meets \\
\hline \multirow{11}{*}{$\begin{array}{l}\text { V. Instructional materials and } \\
\text { technologies }\end{array}$} & \multirow{3}{*}{ A. Structure and design } & 1. Scrolling & Meets \\
\hline & & 2. Consistency & Meets \\
\hline & & 3. Fonts & Meets \\
\hline & \multirow{3}{*}{ B. Use of multimedia } & 1. Technical requirements & Meets \\
\hline & & 2. Audio standards & Meets \\
\hline & & 3. Video standards & Meets \\
\hline & \multirow{3}{*}{ C. Use of images } & 1. Image quality & Meets \\
\hline & & 2. Image file size & Meets \\
\hline & & 3. Animation of images & Meets \\
\hline & \multirow{2}{*}{ D. Links and navigation } & 1. Consistency & Meets \\
\hline & & 2. Hyperlink identity & Meets \\
\hline
\end{tabular}

${ }^{24}$ The Family Educational Rights and Privacy Act of 1974 is a United States federal law that governs the access to educational information and records by public entities such as potential employers, publicly funded educational institutions, and foreign governments.

${ }^{25}$ Related to website compliance with the Americans with Disabilities Act (ADA). 


\begin{tabular}{|c|c|c|c|}
\hline Category & Standard & Characteristic & Rating \\
\hline & & 3. Hyperlink function & Meets \\
\hline & & 4. Hyperlink target & Developing \\
\hline & E. Technologies outside the LMS & & Not applicable \\
\hline \multirow{16}{*}{ VI. Accessibility } & \multirow{2}{*}{ A. Images and graphics } & 1. Alt text & Not applicable \\
\hline & & 2. Captions & Developing \\
\hline & \multirow{4}{*}{ B. Audio, video, and multimedia } & 1. Player controls & Meets \\
\hline & & 2. Closed captions & Non-existent \\
\hline & & 3. Transcripts & Non-existent \\
\hline & & 4. User controls & Meets \\
\hline & \multirow{5}{*}{$\begin{array}{l}\text { C. Documents (HTML, Word, } \\
\text { PowerPoint, Excel, etc) }\end{array}$} & 1. Logically ordered & Meets \\
\hline & & 2. Table titles & Not applicable \\
\hline & & 3. Hyperlinks & Not applicable \\
\hline & & 4. Mobile compatible & Meets \\
\hline & & 5. Table headers & Not applicable \\
\hline & \multirow{2}{*}{ D. Navigation } & 1. Keyboard navigation & Meets \\
\hline & & 2. Tabbing order & Developing $^{*}$ \\
\hline & \multirow{3}{*}{ E. Colours } & 1. Contrast & Developing \\
\hline & & 2. Convey information & Meets \\
\hline & & 3. High contrast settings & Meets \\
\hline \multirow{3}{*}{ VII. Course evaluation } & \multirow{3}{*}{ A. Layout and design } & 1. Physical course & Developing \\
\hline & & 2. Instruction & Developing \\
\hline & & 3. Content & Developing \\
\hline
\end{tabular}

* Ratings marked with an asterisk are the 'characteristics' where the raters had an initial discrepancy. 


\section{Appendix B - Embedded Course Evaluation}




\section{Course Evaluation}

Course Completed:

Clinical Supervision Online

This survey will take approximately 5 minutes. We appreciate you taking the time to complete this survey. Your feedback will help us understand what is important to you so we can improve your experience.

\section{Course Administration}

Instruction emails were useful and clear *

Strongly

Agree

Disagree

Strongly

Not

Support services were easy to access *

Agree

$\bigcirc$

Disagree

Applicable

The support team were knowledgeable

with their responses *

The support team were prompt with their responses *

The academic team were prompt with their responses *

$\bigcirc$

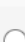

$\bigcirc$

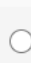

$\bigcirc$

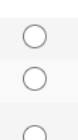

$\bigcirc$

$\bigcirc$

$\bigcirc$

$\bigcirc$

Do you have any additional comments regarding course administration?

\section{Course Delivery}

It was easy to access course materials online with the webviewer *

It was easy to install the app on my device *

The app was easy to use *

The assessment portal was user-friendly *

The course content was interactive *

\begin{tabular}{|c|c|c|c|c|}
\hline $\begin{array}{c}\text { Strongly } \\
\text { Agree }\end{array}$ & Agree & Disagree & $\begin{array}{l}\text { Strongly } \\
\text { Disagree }\end{array}$ & $\begin{array}{c}\text { Not } \\
\text { Applicable }\end{array}$ \\
\hline$\bigcirc$ & (2) & $\bigcirc$ & $\bigcirc$ & $\bigcirc$ \\
\hline$\bigcirc$ & $\bigcirc$ & $\bigcirc$ & $\bigcirc$ & (2) \\
\hline 0 & $\bigcirc$ & $\bigcirc$ & $\mathrm{O}$ & (2) \\
\hline$\bigcirc$ & (2) & $\bigcirc$ & 0 & $\bigcirc$ \\
\hline$\bigcirc$ & () & $\bigcirc$ & $\bigcirc$ & $\bigcirc$ \\
\hline
\end{tabular}

Do you have any additional comments regarding course delivery? 


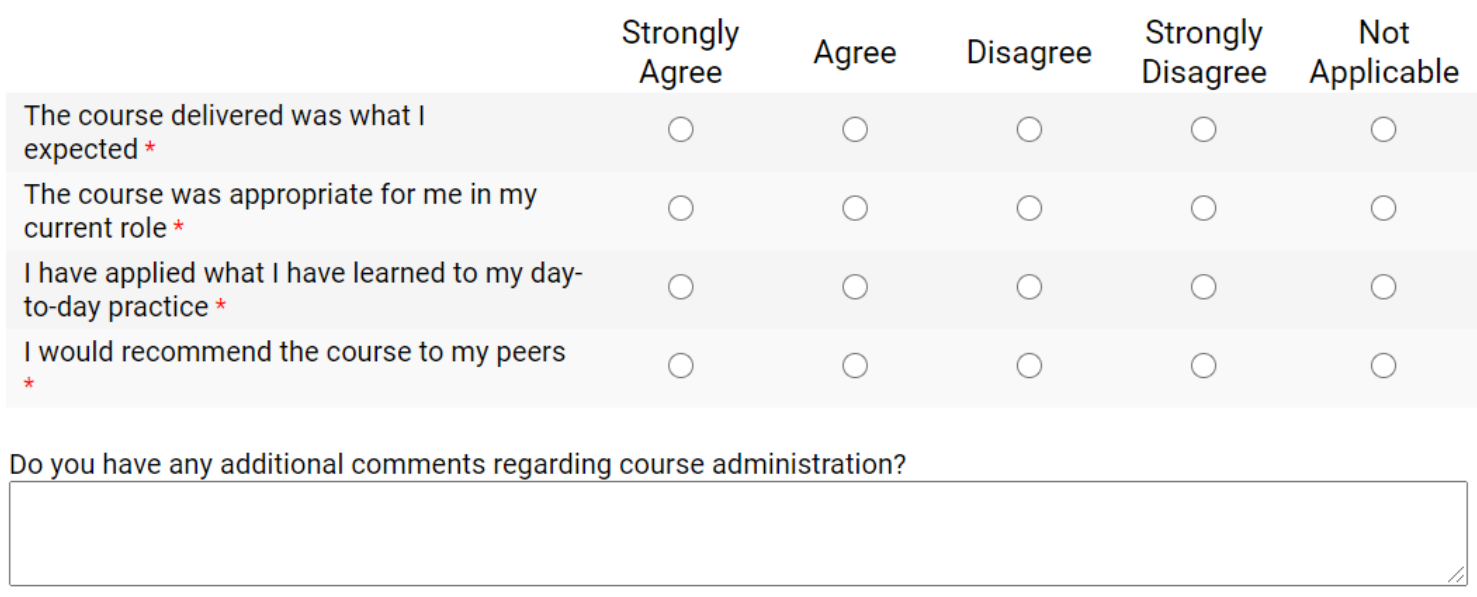

Please estimate how many hours you used the simulator for (if not applicable, please fill in N/A): *

Thank you for taking the time to provide us with your feedback. Your certicate will be emailed shortly after pressing 'Submit'.

\section{Submit}

\section{Notes}

1. There is a significant typographical error in the first open textbox in the Course Impact section, where the request for 'comments regarding course administration' is repeated. This error undoubtedly reduced the usefulness of the responses in this section.

2. The second open textbox in the Course Impact section refers to another course offered by the Mobile Learning Unit. This irrelevant question was confusing for respondents. 


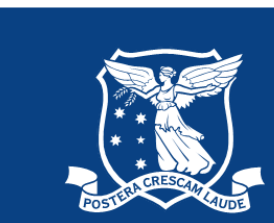

THE UNIVERSITY OF

MELBOURNE

( ( ( 作 要, 促 要, ( P ( U ( ( P N ( 促 N 乎 N (N) N N NA ( N N ( N P $\sim \sim N O N$ 


\section{University Library}

\section{- M M I E E R VA A gateway to Melbourne's research publications}

Minerva Access is the Institutional Repository of The University of Melbourne

Author/s:

Clement, T; Vaughan, B

Title:

Evaluation of a mobile learning platform for clinical supervision

Date:

2021

Citation:

Clement, T. \& Vaughan, B. (2021). Evaluation of a mobile learning platform for clinical supervision. University of Melbourne.

Persistent Link:

http://hdl.handle.net/11343/275644

License:

CC BY 